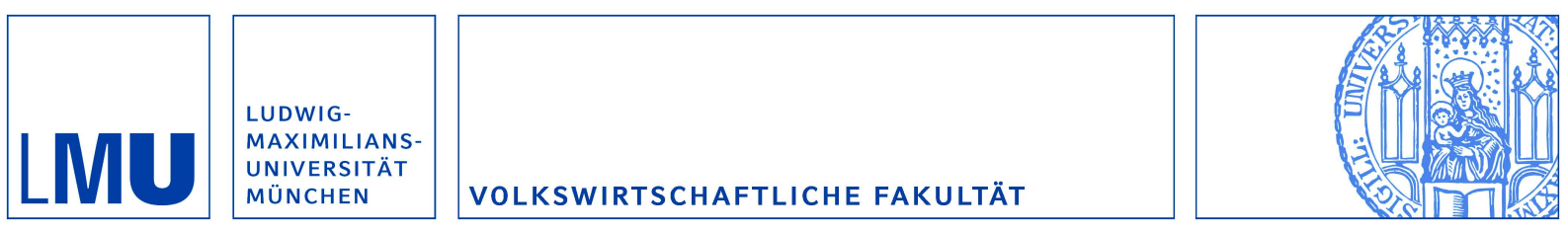

\title{
Lehner, Maria:
}

\section{Entry Mode Choice of Multinational Banks}

Munich Discussion Paper No. 2008-26

Department of Economics

University of Munich

Volkswirtschaftliche Fakultät

Ludwig-Maximilians-Universitäł München

Online at https://doi.org/10.5282/ubm/epub.8222 


\title{
Entry Mode Choice of Multinational Banks
}

\author{
Maria Lehner
}

December 2008

\begin{abstract}
When expanding abroad, a multinational bank faces a trade-off between accessing a foreign country via cross border lending or a financial foreign direct investment, i.e. greenfield or acquisition entry. We analyze the entry mode choice of multinational banks and explicitly derive the entry mode pattern in the banking industry. Moreover, we show that in less developed banking markets, a trend towards cross border lending and acquisition entry exists. Greenfield entry prevails in more developed markets. Furthermore, we identify a tendency towards acquisition entry in small and towards greenfield entry in larger host countries.
\end{abstract}

JEL classification: F37, G21, G34, L13, O16

Keywords: foreign bank entry, multinational bank, cross border lending, greenfield entry, acquisition entry 


\section{Introduction}

The last few years have seen an impressive liberalization of banking markets. While banks active in rather saturated developed financial markets looked for new investment and growth opportunities, banks in many emerging economies were in need for fresh capital in the aftermath of banking crises. The privatization process in Eastern Europe provided further opportunities for multinational banks to expand abroad. Nowadays, in around 40 percent of all developing countries, more than 50 percent of banks are foreign owned. Strikingly, this figure rises to more than 80 percent in several Eastern European countries (Claessens et al., 2008).

This immense transformation of banking markets triggers several questions concerning both the incentives of multinational banks to enter new markets and the incentives of host countries as how to shape foreign entry. Should a multinational bank grant cross border loans or rather access a new market via de novo investment or the acquisition of a local bank? How do the development and the size of the local banking market affect a multinational bank's entry mode choice? What are the host country policy maker's preferences regarding different entry modes of foreign banks?

With the aim to address these questions, we set up a model of spatial bank competition à la Salop. Foreign banks may enter the host country via cross border lending, de novo investment or the acquisition of a domestic bank. Banks compete in interest rates for potential borrowers that engage in investment projects of uncertain return. Foreign banks have access to a better screening technology and enjoy lower refinancing costs than local banks. However, besides market entry costs, foreign banks are at a disadvantage relative to domestic banks in that the latter hold soft information on borrowers due to prior lending relationships. Furthermore, granting cross border loans implies a rather limited knowledge of the host market. Hence, when multinational banks decide about their mode of entry, they face a trade-off between the size of market entry costs and their relative disadvantage in what concerns access to soft information and their knowledge of the local market.

We demonstrate that multinational banks choose their entry mode according to their efficiency in screening potential borrowers. If a bank is rather inefficient in screening, it chooses not to expand abroad. With increasing efficiency, cross border lending becomes feasible. As soon as the better market knowledge in case of greenfield entry compared to cross border lending compensates for the larger fixed entry cost, the foreign bank shifts from cross border lending to de novo investment. Only if the screening technology of the foreign bank is powerful enough, it can drive down the acquisition price to the point that acquisition entry becomes the dominant entry mode.

A major focus of our study is to explain how a foreign bank's entry mode choice is affected by the financial development and the size of the host banking market. Indicators for the host country's level of financial development in our model are the screening efficiency and refinancing conditions of local relative to foreign banks. As a further indicator serves the 
importance of access to soft information as a measure of a market's transparency. A high level of competitive pressure is yet another sign for increased development. We show that in less developed host banking markets a wider range of foreign banks opt for cross border lending and acquisition entry whereas the range of foreign banks that prefer greenfield investment contracts. Interestingly, a wider range of foreign banks favors acquisition entry in smaller host banking markets whereas the attractiveness of de novo investment is enhanced in larger markets.

Our welfare analysis allows us to determine the preferences of the host country policy maker concerning foreign bank entry. The policy maker prefers a foreign bank not to enter the market when it is rather inefficient in screening borrowers. From the policy maker's point of view, cross border lending is strictly dominated by greenfield entry. Greenfield entry, in turn, is favored for intermediate screening efficiencies of foreign banks. If a foreign bank is highly efficient in screening borrowers, the policy maker prefers the foreign bank to acquire a local bank. Although the policy maker's preferences regarding foreign entry are similar to those of foreign banks, scope for regulation exists as the threshold values determining the preferred entry mode pattern of the policy maker and the foreign banks differ.

We find that the regulation of foreign bank entry is shaped as follows. Entry is permitted but to foreign banks that rather efficiently screen borrowers. Furthermore, the less competitive the market environment is, the more likely it is that foreign banks are denied entry. Cross border lending is not allowed for. Foreign banks that intend to expand via cross border lending or the acquisition of a local bank are forced to enter via de novo investment if their screening efficiency is insufficiently low.

The remainder of this paper is organized as follows. The next section reviews the literature. Section 3 describes the set-up of the model. In section 4, we study the entry mode choice of multinational banks. Comparative statics in section 5 allow us to analyze the impact of the financial development as well as the size of the host banking market on the entry mode decision of foreign banks. We present the welfare analysis in section 6. Empirical hypotheses are stated in section 7. Section 8 concludes.

\section{Related Literature}

The massive expansion of multinational banks into emerging markets and transition countries over the last years has spurred the analysis of how host banking markets are affected by the entry of foreign banks. For instance, Martínez Pería and Mody (2004) empirically analyze the impact of foreign bank entry on the efficiency of host banking markets. They find lower interest rate spreads of foreign relative to domestic banks and that increased foreign bank participation decreases overall costs in the banking sector. The influence of foreign bank entry on credit stability is addressed by de Haas and van Lelyveld (2006). Their study implies that 
the credit supply of foreign banks remains stable during crisis periods in the host country but that this effect is mainly driven by greenfield foreign banks. Dell'Ariccia and Marquez (2004) point to the trade-off between superior information of host country banks and lower refinancing costs of foreign banks entering the market. Sengupta (2007) incorporates this tradeoff into a theoretical model in order to find out which market segment foreign banks serve. His analysis shows that foreign banks tend to serve large firms while domestic banks lend to riskier market segments. He concludes that stronger legal protection can overcome informational barriers of foreign banks and, in turn, facilitate entry. Claeys and Hainz (2006) analyze the impact of foreign entry on competition in the host country. In line with Sengupta (2007) they assume that foreign banks have a cost advantage, though here in the form of a better screening technology, whereas domestic banks have an informational advantage concerning old borrowers. In contrast to Sengupta (2007), they distinguish between two forms of market entry, greenfield investment and acquisition. It follows from their analysis that the mode of entry determines the information distribution between foreign and domestic banks which, in turn, affects the degree of competition. Claeys and Hainz (2006) conclude that greenfield investment leads to more competition in the host country than acquisition.

Our model builds on similar assumptions as Dell'Ariccia and Marquez (2004), Sengupta (2007), and Claeys and Hainz (2006) in that we also assume an informational advantage of domestic banks and superior screening skills of foreign banks. However, we do not focus on how foreign entry affects the host banking market but on how foreign banks decide to expand abroad. Although the impact of foreign entry on host banking markets has been studied quite extensively, the expansion of multinational banks and, even more so, their entry mode choice has received astonishingly little attention in the finance literature so far. Our aim is to fill this void. In contrast to Sengupta (2007) and Claeys and Hainz (2006) we explicitly derive under which conditions a multinational bank expands via cross border lending, greenfield investment or acquisition. Our analysis sets in one step before Sengupta (2007). We do not analyze how entry of foreign banks can be facilitated but whether and in which form the policy maker of the host country wants entry to take place. This allows us to derive some implications concerning the regulation of foreign bank entry.

In that we account for a full range of possible entry modes of foreign banks, our paper adds to the so far relatively scarce literature on how foreign banks decide about their entry mode. Buch and Lipponer (2007) and García Herrero and Martínez Pería (2007) empirically analyze the decision of multinational banks to expand abroad via cross border lending or via a financial foreign direct investment but do not explicitly distinguish between greenfield investment and acquisition. They find that the larger the host banking market, the more a foreign direct investment is preferred over cross border activities. Van Tassel and Vishwasrao (2007) as well as Beermann (2007) set up models to study the trade-off between greenfield and acquisition entry. Van Tassel and Vishwasrao conclude that a multinational bank generally favors acquisition over de novo entry. Beermann shows that the most efficient banks choose to expand via the acquisition of a host country bank whereas less efficient banks opt for greenfield entry. 
Our paper is further related to two strands of literature, namely trade theory and industrial organization literature. Trade theory explains a firm's decision to expand abroad via exports (the equivalent to cross border lending) or a foreign direct investment (the equivalent to a financial foreign direct investment). One of the first models in trade theory to study the export versus foreign direct investment decision of firms is Brainard (1993). She points to the trade-off between fixed and variable costs. Firms choose to export in case of high fixed and low variable costs and to serve the foreign market via a foreign direct investment otherwise. Helpman, Melitz and Yeaple (2004) incorporate firm heterogeneity into this trade-off between variable and fixed costs. They show that when countries open up to trade, the least productive firms are forced to exit the market and the remaining firms engage with increasing labor productivity in exports before they start to operate in a new market via a foreign direct investment. Nocke and Yeaple (2004) theoretically analyze the decision of a firm to expand via de novo investment or the acquisition of a local firm and conclude that the most efficient firms opt for de novo investment. In a related paper, Nocke and Yeaple (2007) distinguish between exports, greenfield and acquisition entry and suggest that the entry mode choice of firms depends on whether foreign and host country firms differ in mobile or immobile capabilities.

Related articles in the industrial organization literature focus on the trade-off between greenfield and acquisition entry. Gilroy and Lukas (2006), Görg (2000), Iranzo (2003), as well as Raff et al. (2006) set up models in which a firm's decision between greenfield and acquisition entry depends on differences in the marginal costs of foreign and domestic firms. As in Eicher and Kang (2005) or Müller (2007), it is generally assumed that a greenfield entrant produces at lower marginal costs than domestic firms. This is motivated by the foreign firm's superior production technology of which it can take full advantage when building its own production facilities from scratch. At the same time, however, this implies huge fixed market entry costs. In contrast, if entry occurs via acquisition, the foreign firm is presumed to be constrained to the use of the inferior production facilities of the acquired firm and, in addition, the need to restructure the target firm. In turn, this implies higher marginal costs of the foreign compared to the domestic firm. Most of these papers conclude that rather productive firms opt for de novo investment whereas less productive firms favor the acquisition of a domestic firm.

The situation in the banking industry is different. A multinational bank that enters a new market via de novo investment faces a disadvantage relative to domestic banks in that the latter hold soft information on borrowers due to prior lending relationships. Consequently, when a foreign bank opts for greenfield entry, it may incur higher variable costs than the domestic banks. However, if a multinational bank decides to enter a new market via the acquisition of a host country bank, it gains access to the soft information held by the target. Moreover, the entrant can relatively easily implement its own superior screening technology. As a result, the entrant may operate at lower marginal costs than domestic banks.

Hence, we add to the trade and industrial organization literature with its focus on manufacturing industries in that we account for special characteristics of the banking sector. We depart 
from trade theory in that our model is not based on monopolistic competition. Rather, banks in our model compete in prices which we consider a more appropriate form of competition in the banking industry. Furthermore, instead of labor productivity we rely on a bank's screening efficiency as the key indicator of its productivity since it determines the quality of its credit portfolio. Moreover, we add to the industrial organization literature in that we stress that the foreign banks' lack of access to soft information may imply the reversal of the pattern of marginal costs as described above. As in the industrial organization literature, we allow for restructuring costs but emphasize that they should be of a rather fixed nature.

\section{The Model}

We consider two separated banking markets, $A$ and $B$. Multinational banks are based in market $A$. Market $B$ represents the host banking market. In market $B$, a continuum of borrowers with mass $m$ is uniformly distributed along a circular road with circumference 1 . Each borrower can engage in one investment project that requires an initial outlay of 1 . Borrowers can either invest in good or in bad projects. It is common knowledge that the fraction of borrowers with good projects is $\gamma$ and the fraction of borrowers with bad projects is $1-\gamma, 0<\gamma<1$. Individual borrowers know about the quality of their own investment projects. In case the project is good it generates a return $v>0$ with certainty while a bad project always fails yielding a return of zero. The returns of the projects are observable and contractible. Borrowers are not endowed with any initial wealth and therefore need to apply for credit at the banks, the only source of finance in our model.

Before market $B$ is opened up to the entry of a foreign bank, two identical representative banks $B_{j}, j=1,2$, are located equidistantly along the circular road. The location of a bank reflects its specialization in a certain credit product or industry. Banks compete in the interest rates $r_{B_{j}}$ they simultaneously charge borrowers. Borrowers whose investment project yields a return of $v$ repay their loan with interest to the bank whereas borrowers whose project fails do not repay their loan. Host country banks incur refinancing costs $i_{B}>0$ per loan of size 1. They have access to an imperfect screening technology based on the evaluation of hard information provided by borrowers. It allows the local banks to identify the fraction $\delta_{B}$, $0<\delta_{B}<1$, of borrowers investing in bad projects. The banks cannot distinguish between the remaining borrowers with bad projects and borrowers investing in good projects. Hence, the fraction $\left(1-\delta_{B}\right)$ of bad borrowers and all good borrowers applying for credit obtain financing. Without loss of generality, we assume that screening is costless for all banks.

When the host banking market opens up to foreign bank entry, a foreign bank based in market $A$ is granted the permission to enter market $B$. Without loss of generality we abstract from relocation costs and assume that after foreign entry, banks are located equidistantly along the circular road. We assume that the foreign bank has access to a superior screening technology 
relative to domestic banks. Its screening technique allows the foreign bank to identify a fraction $\delta_{A}, 0<\delta_{B}<\delta_{A}<1$, of borrowers investing in bad projects. Furthermore, we assume lower refinancing costs of foreign banks compared to host country banks, i.e. $0<i_{A}<i_{B} \cdot{ }^{1}$ The foreign bank may enter market $B$ via cross border lending, de novo investment, or the acquisition of a domestic bank.

When a foreign bank enters the host country via cross border lending or de novo investment, it encounters a disadvantage relative to domestic banks in what concerns the access to soft information about borrowers. In contrast to hard information, soft information needs to be collected over time through relationships with clients (Petersen and Rajan, 1994; Stein, 2002). As in Sengupta (2007), we assume that domestic banks were able to collect unobservable, i.e. soft information on their borrowers during past lending relationships. In the literature, there are different approaches to capture the soft information advantage of domestic relative to foreign banks. Dell'Ariccia et al. (1999) and Dell'Ariccia (2001) base their model on the existence of new and old borrowers so that domestic banks have an advantage over foreign banks concerning the share of old borrowers. Gormley (2008) interprets the information advantage of domestic versus foreign banks as higher per borrower screening costs of the latter. For our analysis, it is convenient to model the lack of soft information about borrowers as a decline in the power of the foreign bank's screening technology. We assume that in case of cross border lending and greenfield entry, the quality of the foreign bank's screening technology is diminished by a factor $\mu, 0<\mu<1$. Hence, only the share $\mu \delta_{A}$ of borrowers with bad projects is identified. However, the acquisition of a local bank ensures access to the soft information held by the target which implies that the fraction $\delta_{A}$ of borrowers with bad projects is denied credit. We assume that all borrowers apply for a loan with new investment projects. Hence, although domestic banks have access to soft information about potential clients, both foreign and domestic banks need to screen borrowers.

In our model, we also consider the foreign bank's fairly limited knowledge of the host banking market if it grants cross border loans and, accordingly, has no large presence in the local banking market. We capture this limited market knowledge by an even lower quality of the foreign bank's screening technology. That is, only the share $\alpha \mu \delta_{A}, 0<\alpha<1$, of borrowers investing in bad projects is identified in case of cross border lending. ${ }^{2}$

When the foreign bank starts to operate in market $B$, it incurs market entry costs. Entry costs are modeled as a fixed component in case of cross border lending, $F_{C B L}$, and greenfield entry, $F_{G R}, F_{C B L}<F_{G R}$. Note that in case of greenfield entry the foreign bank needs to establish a new branch network, whereas with cross border lending, it may only set up a representative

\footnotetext{
${ }^{1}$ These assumptions are confirmed by e.g. Berger (2007), Gormley (2008), and Sengupta (2007).

${ }^{2}$ Note that in case of cross border lending and greenfield entry either the foreign bank or the domestic bank may be better in identifying borrowers with bad projects, depending on the foreign bank's market knowledge $\alpha$ and the extent of soft information problems $\mu$. In case of acquisition entry, however, the foreign bank is always better in screening borrowers than the domestic bank since the foreign bank has access to the soft information held by the target.
} 
office which is much less costly. When a multinational bank enters a new market via the acquisition of a domestic bank, the foreign bank's entry cost consists of the endogenous takeover price $P_{A C}$ and a fixed component $F_{A C}$, with $F_{G R}<P_{A C}+F_{A C}$. The fixed component may reflect, for instance, restructuring costs or the amortization of bad credits due to asymmetric information concerning the quality of the target's credit portfolio before the acquisition. ${ }^{3}$

Banks compete in the interest rates $r_{A}$ and $r_{B_{j}}$ they simultaneously ask from borrowers. Borrowers base their decision at which bank to apply for credit on the interest rates offered by the banks and the transport costs they have to incur to travel to the bank. The transport costs express the preferences borrowers have for a particular type of bank. We assume that transport costs $t x$ are proportional to the distance $x$ between the borrower and the bank. Furthermore, we assume that the return of a good project $v$ is high enough so that in equilibrium it is profitable for every borrower to take out a loan independent of the borrower's location between two banks. More specifically, we assume $v>\frac{3}{4} t+\frac{1}{2 \gamma}\left\{i_{B}+i_{A}+(1-\gamma)\left[2-\delta_{B}\left(1+i_{B}\right)-\delta_{A}\left(1+i_{A}\right)\right]\right\}$.

Borrowers and banks are risk neutral and maximize profits. We take it as given that each bank disposes of enough funds to finance all borrowers applying for a credit. We assume that banks can observe the location of borrowers. ${ }^{4}$ Borrowers with bad projects that are denied credit do not apply for credit at another bank because banks can deduce from the borrowers' location that they have unsuccessfully applied for a loan at another bank.

The time structure of the game is as follows. At stage 1, market $B$ opens up to the entry of one representative foreign bank. At stage 2, borrowers apply for credit at the banks. Banks engage in screening the borrowers. At stage 3, returns realize and all borrowers having invested in good projects pay back their loan.

\section{Choice of Entry Mode}

In this section, we study the incentives of the foreign bank to grant cross border loans or to expand via greenfield investment or the acquisition of a domestic bank. For expositional clarity we proceed as follows. We first look at how the decision of the foreign bank to concede cross border loans or to not expand abroad is determined by the foreign bank's screening ability. Then, we incorporate the option of greenfield investment and determine how this modifies the entry mode choice of the foreign bank. Finally, we further allow for the acquisition of a domestic bank. Hence, our aim is to derive the entry mode pattern of foreign banks depending on the degree of their screening efficiency.

\footnotetext{
${ }^{3}$ Note that our assumptions concerning entry costs ensure that the richest possible entry mode pattern is indeed achieved. Without these assumptions, some entry modes may drop out of the pattern. However, it is important to see that without these assumptions, the order of the entry mode pattern would not change.

${ }^{4}$ As e.g. in Dell'Ariccia (2001), this assumption considerably simplifies our analysis. Note that we abstract from the possibility of price discrimination of borrowers.
} 


\subsection{Cross Border Lending}

The foreign bank enters market $B$ via cross border lending if it thereby makes positive profits in the host banking market. The profit of the foreign bank in the host banking market is given by

$$
\pi_{A}^{C B L}=\left[\gamma\left(r_{A}^{C B L}-i_{A}\right)-(1-\gamma)\left(1-\alpha \mu \delta_{A}\right)\left(1+i_{A}\right)\right] m \phi_{A}^{C B L}-F_{C B L} .
$$

When the foreign bank offers cross border loans, it has no access to soft information about borrowers and, in addition, a fairly limited knowledge of the local banking market. Hence, the foreign bank identifies a rather low fraction $\alpha \mu \delta_{A}$ of borrowers with bad projects but cannot distinguish between the remaining fraction $\left(1-\alpha \mu \delta_{A}\right)$ of bad borrowers and the borrowers with good projects. Accordingly, the foreign bank finances the fraction $\left(1-\alpha \mu \delta_{A}\right)$ of borrowers investing in bad projects as well as all borrowers with good projects applying for credit. Since bad borrowers do not make any repayments, the foreign bank incurs a cost of $1+i_{A}$ on this group. The fraction $\gamma$ of good borrowers, however, repays the loan with interest so that the bank obtains the margin $r_{A}^{C B L}-i_{A}$ on those clients. The market share of the foreign bank is derived in the Appendix (see proof of Lemma 1) and is given by $m \phi_{A}^{C B L}=m\left(\frac{1}{3}+\frac{r_{B_{1}}^{C B L}+r_{B_{2}}^{C B L}-2 r_{A}^{C B L}}{2 t}\right)$. Fixed entry costs amount to $F_{C B L} \cdot{ }^{5}$

Host country banks do not incur any soft information problems or fixed costs. Accordingly, their profit is given by

$$
\pi_{B_{j}}^{C B L}=\left[\gamma\left(r_{B_{j}}^{C B L}-i_{B}\right)-(1-\gamma)\left(1-\delta_{B}\right)\left(1+i_{B}\right)\right] m \phi_{B_{j}}^{C B L}, \quad j=1,2
$$

with $\phi_{B_{1}}^{C B L}=\frac{1}{3}+\frac{r_{A}^{C B L}+r_{B_{2}}^{C B L}-2 r_{B_{1}}^{C B L}}{2 t}$ and $\phi_{B_{2}}^{C B L}=\frac{1}{3}+\frac{r_{A}^{C B L}+r_{B_{1}}^{C B L}-2 r_{B_{2}}^{C B L}}{2 t}$.

Banks maximize their profit with respect to the interest rates they ask from borrowers. We state the resulting equilibrium profits in Lemma 1:

Lemma 1 If foreign bank entry takes place via cross border lending, equilibrium profits of banks are given by

$$
\begin{aligned}
& \pi_{A}^{C B L}=m t \gamma\left(\widetilde{\phi}_{A}^{C B L}\right)^{2}-F_{C B L} \\
& \pi_{B_{j}}^{C B L}=m t \gamma\left(\widetilde{\phi}_{B}^{C B L}\right)^{2} \equiv \pi_{B}^{C B L} \forall j
\end{aligned}
$$

with $\widetilde{\phi}_{A}^{C B L}=\frac{2}{5 t \gamma}\left[\frac{5}{6} t \gamma+\Delta+\alpha \mu(1-\gamma)\left(1+i_{A}\right) \delta_{A}\right], \widetilde{\phi}_{B}^{C B L}=\frac{1}{5 t \gamma}\left[\frac{5}{3} t \gamma-\Delta-\alpha \mu(1-\gamma)\left(1+i_{A}\right) \delta_{A}\right]$ and $\Delta=i_{B}-i_{A}-(1-\gamma)\left(1+i_{B}\right) \delta_{B}$.

Proof: see Appendix.

\footnotetext{
${ }^{5}$ In our analysis, we focus on the interaction of foreign and domestic banks and, therefore, abstract from the possible exit of domestic banks.
} 
The foreign bank enters the host banking market via cross border lending as soon as the quality of its screening technology allows it to make positive profits in market $B$, that is, $\pi_{A}^{C B L} \geq 0$. Our result is stated in Proposition $1 .^{6}$

Proposition 1 The foreign bank enters the host banking market via cross border lending if its screening efficiency is higher than the threshold value $\delta_{A}^{C B L}$. That is, if

$$
\delta_{A} \geq \delta_{A}^{C B L}=\frac{\frac{5}{2} \sqrt{\frac{t \gamma F_{C B L}}{m}}-\Delta-\frac{5}{6} t \gamma}{\alpha \mu(1-\gamma)\left(1+i_{A}\right)} .
$$

Proof: see Appendix.

\subsection{Greenfield Investment}

When the foreign bank enters the host market via de novo investment, it gains a fairly good knowledge of the local market due to its large presence and branch network. Yet, it has no access to soft information about borrowers. Compared to cross border lending, the foreign bank finances a smaller fraction $\left(1-\mu \delta_{A}\right)$ of borrowers with bad projects. However, it incurs a larger fixed entry cost $F_{G R}$. The foreign bank's profit in market $B$ is given by

$$
\pi_{A}^{G R}=\left[\gamma\left(r_{A}^{G R}-i_{A}\right)-(1-\gamma)\left(1-\mu \delta_{A}\right)\left(1+i_{A}\right)\right] m \phi_{A}^{G R}-F_{G R}
$$

with $\phi_{A}^{G R}=\frac{1}{3}+\frac{r_{B_{1}}^{G R}+r_{B_{2}}^{G R}-2 r_{A}^{G R}}{2 t}$.

Profits of host country banks now amount to

$$
\pi_{B_{j}}^{G R}=\left[\gamma\left(r_{B_{j}}^{G R}-i_{B}\right)-(1-\gamma)\left(1-\delta_{B}\right)\left(1+i_{B}\right)\right] m \phi_{B_{j}}^{G R}, \quad j=1,2
$$

with $\phi_{B_{1}}^{G R}=\frac{1}{3}+\frac{r_{A}^{G R}+r_{B_{2}}^{G R}-2 r_{B_{1}}^{G R}}{2 t}$ and $\phi_{B_{2}}^{G R}=\frac{1}{3}+\frac{r_{A}^{G R}+r_{B_{1}}^{G R}-2 r_{B_{2}}^{G R}}{2 t}$.

Banks maximize their profit with respect to the interest rates they ask from borrowers. The equilibrium profits of banks are stated in Lemma 2.

\footnotetext{
${ }^{6}$ Note that, in principle, there may be scope for a host country bank to enter the market instead of a foreign bank. Such a situation would not arise if the starting point of our analysis were a free entry equilibrium of domestic banks. However, the main effect of a higher number of domestic banks in the market is to drive down the profit margin of all banks implying a shift of thresholds to the right but leaving the qualitative results unchanged. Besides, free entry does not take place in the banking sector of many transition and emerging market economies. The decision over the entry of a bank is very often a case by case analysis and a rather intransparent process. Even if well-defined regulatory laws exist, measures such as the delay of licensing procedures allow policy makers to deny entry to a domestic bank and to hand out a license to a foreign bank if so desired. Since the aim of our analysis is not to compare the impact of foreign versus domestic entry but to analyze the determinants of different entry modes of foreign banks, we abstract from entry of domestic banks.
} 
Lemma 2 In case of greenfield entry, the equilibrium profits of banks are given by

$$
\begin{aligned}
& \pi_{A}^{G R}=m t \gamma\left(\widetilde{\phi}_{A}^{G R}\right)^{2}-F_{G R} \\
& \pi_{B_{j}}^{G R}=m t \gamma\left(\widetilde{\phi}_{B}^{G R}\right)^{2} \equiv \pi_{B}^{G R} \forall j
\end{aligned}
$$

with $\widetilde{\phi}_{A}^{G R}=\frac{2}{5 t \gamma}\left[\frac{5}{6} t \gamma+\Delta+\mu(1-\gamma)\left(1+i_{A}\right) \delta_{A}\right]$ and $\widetilde{\phi}_{B}^{G R}=\frac{1}{5 t \gamma}\left[\frac{5}{3} t \gamma-\Delta-\mu(1-\gamma)\left(1+i_{A}\right) \delta_{A}\right]$.

Proof: see Appendix.

We show in the Appendix (see proof of Proposition 2) that due to the better knowledge of the host banking market, the profit of the foreign bank rises more sharply in the screening technology $\delta_{A}$ in case of de novo investment than in case of cross border lending. However, the fixed entry cost is larger with greenfield entry. Hence, as soon as the better market knowledge compensates for the larger fixed entry cost, the foreign bank shifts from cross border lending to de novo investment at the threshold $\delta_{A}^{G R}$, originating from $\pi_{A}^{G R} \geq \pi_{A}^{C B L}$. Note that we concentrate our analysis on the most interesting case of the richest possible entry mode pattern, i.e. we only consider $\delta_{A}^{G R}>\delta_{A}^{C B L}{ }^{7}$ Our results are given in Proposition 2.

Proposition 2 The foreign bank opts for greenfield entry if its screening efficiency is higher than the threshold value $\delta_{A}^{G R}$. That is, if

$$
\delta_{A} \geq \delta_{A}^{G R}=\frac{\sqrt{X_{G R}}-\Delta-\frac{5}{6} t \gamma}{\mu(1+\alpha)(1-\gamma)\left(1+i_{A}\right)}
$$

with $X_{G R}=\left(\Delta+\frac{5}{6} t \gamma\right)^{2}+\frac{25 t \gamma(1+\alpha)\left(F_{G R}-F_{C B L}\right)}{4 m(1-\alpha)}$.

Proof: see Appendix.

\subsection{Entry via Acquisition}

By acquiring a host country bank, the foreign bank gets access to all the soft information held by the target. However, it must pay the endogenous acquisition price $P_{A C}$. Furthermore, it incurs an additional fixed entry cost $F_{A C}$. This cost may originate from the restructuring of the acquired bank or the amortization of bad credits due to asymmetric information concerning the quality of the target's credit portfolio before the acquisition. Note that the acquisition of a domestic bank allows the foreign bank to capture a larger market share in comparison to all other entry modes. In addition, the foreign bank gains from less intense competition since just

\footnotetext{
${ }^{7}$ In principle, $\delta_{A}^{G R}<\delta_{A}^{C B L}$ is possible but in that case, cross border lending would be excluded from the entry mode pattern.
} 
two banks operate in the market. ${ }^{8}$ The profit of the foreign bank in the host banking market if it acquires a local bank is given by

$$
\pi_{A}^{A C}=\left[\gamma\left(r_{A}^{A C}-i_{A}\right)-(1-\gamma)\left(1-\delta_{A}\right)\left(1+i_{A}\right)\right] m \phi_{A}^{A C}-F_{A C}-P_{A C}
$$

with $\phi_{A}^{A C}=\frac{1}{2}+\frac{r_{B}^{A C}-r_{A}^{A C}}{t}$.

The profit of the remaining host country bank amounts to

$$
\pi_{B}^{A C}=\left[\gamma\left(r_{B}^{A C}-i_{B}\right)-(1-\gamma)\left(1-\delta_{B}\right)\left(1+i_{B}\right)\right] m \phi_{B}^{A C}
$$

with $\phi_{B}^{A C}=\frac{1}{2}+\frac{r_{A}^{A C}-r_{B}^{A C}}{t}$.

We now derive the endogenous acquisition price $P_{A C}$. Throughout our analysis, we will assume that bargaining power is allocated to the foreign bank. In the range of $0<\delta_{A}<\delta_{A}^{C B L}$, the foreign bank would make losses by entering the host banking market via cross border lending or greenfield entry. Then, clearly, the acquisition price is given by the profit of the domestic bank in case of no entry, that is, $P_{A C}=\pi_{B}^{N E}=\frac{m t \gamma}{4}$ (for a derivation of $\pi_{B}^{N E}$ see proof of Proposition 3). For $\delta_{A}^{C B L} \leq \delta_{A}<\delta_{A}^{G R}$, cross border lending constitutes the second best entry mode for the foreign bank. Hence, by threatening to enter via cross border lending, the foreign bank can drive down the acquisition price to the profit of the domestic bank if entry occurs via cross border lending, i.e., $P_{A C}=\pi_{B}^{C B L}=m t \gamma\left(\widetilde{\phi}_{B}^{C B L}\right)^{2}$. For $\delta_{A}^{G R} \leq \delta_{A}<1$, greenfield entry constitutes the second best entry mode for the foreign bank. Accordingly, bank $A$ can threaten to enter market $B$ via greenfield entry and drive down the acquisition price to the profit of the domestic bank in case of greenfield entry, that is, $P_{A C}=\pi_{B}^{G R}=\operatorname{mt} \gamma\left(\widetilde{\phi}_{B}^{G R}\right)^{2}$.

Banks maximize their profit with respect to the interest rates they ask from borrowers. Equilibrium profits of banks are stated in Lemma 3.

Lemma 3 In case of acquisition entry, the equilibrium profits of banks are given by

$$
\begin{aligned}
& \pi_{A}^{A C}=\left\{\begin{array}{lll}
m t \gamma\left(\widetilde{\phi}_{A}^{A C}\right)^{2}-\frac{m t \gamma}{4}-F_{A C} & \text { for } \quad 0<\delta_{A}<\delta_{A}^{C B L} \\
m t \gamma\left[\left(\widetilde{\phi}_{A}^{A C}\right)^{2}-\left(\widetilde{\phi}_{B}^{C B L}\right)^{2}\right]-F_{A C} & \text { for } \quad \delta_{A}^{C B L} \leq \delta_{A}<\delta_{A}^{G R} \\
m t \gamma\left[\left(\widetilde{\phi}_{A}^{A C}\right)^{2}-\left(\widetilde{\phi}_{B}^{G R}\right)^{2}\right]-F_{A C} & \text { for } \quad \delta_{A}^{G R} \leq \delta_{A}<1
\end{array}\right. \\
& \pi_{B}^{A C}=m t \gamma\left(\widetilde{\phi}_{B}^{A C}\right)^{2}
\end{aligned}
$$

with $\widetilde{\phi}_{A}^{A C}=\frac{1}{3 t \gamma}\left[\frac{3}{2} t \gamma+\Delta+(1-\gamma)\left(1+i_{A}\right) \delta_{A}\right]$ and $\widetilde{\phi}_{B}^{A C}=\frac{1}{3 t \gamma}\left[\frac{3}{2} t \gamma-\Delta-(1-\gamma)\left(1+i_{A}\right) \delta_{A}\right]$.

Proof: see Appendix.

\footnotetext{
${ }^{8}$ Fiercer competition in the host banking market in case of greenfield compared to acquisition entry is confirmed, for instance, by Claeys and Hainz (2006) and Maioli et al. (2006).
} 
In the Appendix, we show that $\pi_{A}^{A C}$ is increasing in $\delta_{A}$ and jumps upwards twice due to the changing acquisition prices at $\delta_{A}^{C B L}$ and $\delta_{A}^{G R}$. Furthermore, $\pi_{A}^{A C}$ is steeper than both $\pi_{A}^{C B L}$ and $\pi_{A}^{G R}$. Hence, the richest possible entry mode pattern emerges if $\pi_{A}^{A C}$ intersects with $\pi_{A}^{G R}$, determining the threshold for acquisition entry, $\delta_{A}^{A C}$ with $\delta_{A}^{A C} \geq \delta_{A}^{G R}$. Our results regarding acquisition entry are stated in Proposition 3.

Proposition 3 The foreign bank enters the host banking market via the acquisition of a domestic bank if its screening efficiency is higher than the threshold value $\delta_{A}^{A C}$. That is, if

$$
\delta_{A} \geq \delta_{A}^{A C}=\frac{3 t \gamma(5-2 \mu)-2 \Delta(9 \mu-5)}{2\left(9 \mu^{2}-5\right)(1-\gamma)\left(1+i_{A}\right)}\left(1-\sqrt{X_{A C}}\right)
$$

with $X_{A C}=1+\frac{\left(9 \mu^{2}-5\right)\left[\left(5 t^{2} \gamma^{2}+36 t \gamma \Delta-16 \Delta^{2}\right)+\frac{180 t \gamma}{m}\left(F_{G R}-F_{A C}\right)\right]}{(3 t \gamma(5-2 \mu)-2 \Delta(9 \mu-5))^{2}}$.

Proof: see Appendix.

Hence, only if the foreign bank has access to a highly sophisticated screening technique, acquisition entry can dominate all other possible entry modes. The intuition behind this result is as follows. In case of acquisition entry, the profit of the foreign bank rises more sharply in its screening ability than it does in case of cross border lending or greenfield entry. First, this is due to the access to soft information. Second, the better the screening technology of the foreign bank, the lower is the profit of a host country bank in case of de novo entry of the foreign bank and, accordingly, the lower the acquisition price becomes. ${ }^{9}$ Hence, only if the screening technology of the foreign bank is very powerful, it can drive down the acquisition price to the point that acquisition entry becomes the dominant entry mode.

\subsection{Entry Mode Pattern}

According to our analysis so far, the richest entry mode pattern to emerge is given as follows. If the foreign bank has access to a rather inefficient screening ability, entry is not profitable. With an increasing quality of the screening technology, fixed entry costs can be covered so that cross border lending becomes feasible. Due to the foreign bank's better market knowledge in case of greenfield entry compared to cross border lending, a marginal increase in its screening efficiency implies a larger increase in its profit in case of greenfield entry. Hence, for a high enough screening efficiency, the foreign bank can compensate for the larger fixed entry cost and shifts from cross border lending to de novo investment. In case of acquisition entry, a marginal increase in the foreign bank's screening efficiency is not mitigated by lower market knowledge or soft information problems. Furthermore, the acquisition price decreases in the foreign bank's

\footnotetext{
${ }^{9}$ Note that as we limit our analysis to the richest possible entry mode pattern, the acquisition price is given by $\pi_{B}^{G R}$.
} 
efficiency. Hence, for a high enough screening efficiency of the foreign bank, acquisition becomes the dominant entry mode.

Note that we limit our analysis to the richest entry mode pattern. Otherwise, it would be possible that one or more entry modes dropped out of the pattern. However, it is important to see that the order of the entry mode pattern can never be reversed. Our results are summarized in Proposition 4.

Proposition 4 The richest possible entry mode pattern of foreign banks is given as follows. Banks with the lowest screening efficiencies do not expand abroad. With increasing efficiency, banks grant cross border loans. Still more efficient banks opt for de novo investment. The most efficient banks choose to acquire a host country bank. ${ }^{10}$

Hence, in line with findings by Buch and Lipponer (2007) as well as Focarelli and Pozzolo (2001) we find that the more profitable and efficient a bank is, the more likely it will expand abroad. Similar to the results in trade theory, we find that rather less efficient firms engage in cross border lending, the equivalent to exports in our model, whereas more efficient banks operate in new markets via a financial foreign direct investment. However, our results contrast those derived in the industrial organization literature with its focus on manufacturing industries in that we find that the most efficient banks engage in acquisition entry whereas less efficient banks expand abroad via de novo investment. Similar to our results, Beermann (2007) shows that the most efficient banks choose to expand via the acquisition of a local bank whereas less efficient banks opt for greenfield entry.

\section{Comparative Statics Analysis}

Our framework allows us to study how the development of the host banking market affects the foreign bank's entry mode pattern. In addition, we provide interesting insights into how the foreign bank's choice of entry mode depends on the size of the host banking market.

\footnotetext{
${ }^{10}$ Note that our assumption of $i_{A}<i_{B}$ implies that foreign banks can profitably enter the host country with relatively lower screening abilities compared to a scenario in which interest rates were identical. Hence, in contrast to such a scenario, the threshold values determining the entry mode pattern in our set-up are located somewhat to the left. Further effects arising from differences in interest rates are derived in the comparative statics analysis.
} 


\subsection{Development of the Host Banking Market}

In our model, several parameters can be interpreted as indicators of financial development. First, the less banks need to rely on soft information the more transparent and developed a financial market in general is. Second, better screening abilities and lower refinancing costs of host country relative to foreign banks serve as further indicators of development. Finally, a high degree of competitive pressure in the host banking market is yet another sign of increased development.

\section{Importance of Access to Soft Information}

In more developed banking markets characterized by rather high transparency, banks should base the evaluation of borrower's projects to a lower extent on soft information. We find that when foreign banks need to rely less on soft information, i.e. $\mu$ increases, entry turns out to be profitable for foreign banks that have access to a less efficient screening technique. Furthermore, greenfield entry becomes relatively more attractive compared to cross border lending and acquisition entry. Our results are summarized in Proposition 5.

Proposition 5 When foreign banks need to rely less on soft information, entry becomes feasible for banks that have access to a less efficient screening technique. The range of greenfield entry expand whereas the ranges of cross border lending and acquisition entry contract. That is,

$$
\frac{d \delta_{A}^{C B L}}{d \mu}<0, \frac{d \delta_{A}^{G R}}{d \mu}<0, \frac{d \delta_{A}^{A C}}{d \mu}>0 \quad \text { and } \quad\left|\frac{d \delta_{A}^{C B L}}{d \mu}\right|<\left|\frac{d \delta_{A}^{G R}}{d \mu}\right| .
$$

Proof: see Appendix.

To understand the intuition for these results, let us first look at the threshold $\delta_{A}^{C B L}$, determining cross border lending. When the foreign bank depends less on the access to soft information, it can increase its market share and, in addition, less borrowers with bad projects are financed. This makes cross border lending profitable for less efficiently screening foreign banks.

Similar effects are at work when we consider the threshold $\delta_{A}^{G R}$. When the foreign bank needs to rely to a lower extent on soft information, its market share increases and less bad borrowers are financed both with cross border lending and greenfield entry. However, this effect is the more pronounced, the larger the market share of the foreign bank. Since the foreign bank's market share is larger in case of a de novo investment than with cross border lending, greenfield entry becomes relatively more attractive compared to cross border lending when foreign banks depend less on soft information.

We now turn to the attractiveness of acquisition relative to greenfield entry. The acquisition of a domestic bank ensures access to the soft information held by the target. Note that the 
extent to which the foreign bank depends on access to soft information affects the acquisition price $\pi_{B}^{G R}$. The less the foreign bank needs to rely on soft information, the smaller the market share of the domestic bank is if the foreign bank enters via de novo investment. In turn, the acquisition price $\pi_{B}^{G R}$ falls and the foreign bank's profit increases. While the fall in the acquisition price is due to a fall in the domestic bank's market share only, there are two effects at work with respect to the profit of the foreign bank if it enters via de novo investment. First, a lower information disadvantage of the foreign relative to the domestic bank implies a larger market share of the foreign bank and, second, leads to a fall in the fraction of bad borrowers financed by the foreign bank. As a consequence, the increase of the foreign bank's profit in case of greenfield entry dominates the rise in its profit in case of acquisition entry. In sum, greenfield entry becomes more attractive compared to the acquisition of a local bank when access to soft information is less important.

We conclude that foreign banks tend to enter via greenfield entry into banking markets with a higher degree of financial development. In contrast, in less developed banking markets, a wider range of foreign banks opt for cross border lending and acquisition entry.

\section{Quality of the Screening Ability of Host Country Banks}

We find that when the screening ability $\delta_{B}$ of host country banks increases, foreign banks must be relatively better at screening borrowers in order to profitably enter a new market. Furthermore, acquisition entry becomes relatively less attractive compared to greenfield entry. Our results are stated in Proposition 6.

Proposition 6 An increase in the screening ability of host country banks leads to an increase in all relevant threshold levels. Consequently, foreign banks must possess a relatively better screening technology in order to profitably enter the host banking market. The range of acquisition entry contracts. That is,

$$
\frac{d \delta_{A}^{C B L}}{d \delta_{B}}>0, \frac{d \delta_{A}^{G R}}{d \delta_{B}}>0, \frac{d \delta_{A}^{A C}}{d \delta_{B}}>0 .
$$

Proof: see Appendix.

Again, let us first look at the threshold $\delta_{A}^{C B L}$, determining cross border lending. When host country banks get access to a relatively better screening technique, the foreign bank loses in terms of market share. Obviously, entry via cross border lending is then profitable for foreign banks having access to a relatively more sophisticated screening technology only.

When the screening skills of domestic banks improve, the market share and profit of a foreign bank also falls in case of greenfield entry. However, the fall in the foreign bank's profit is larger with greenfield entry compared to cross border lending due to the beforehand larger 
market share. Hence, greenfield entry becomes relatively less attractive compared to cross border lending when domestic banks get better in screening potential borrowers.

We find that when host country banks get access to a better screening technology, acquisition entry becomes less attractive to foreign banks compared to a de novo investment. This is due to a fall in the market share of a foreign bank entering the host banking market via the acquisition of a domestic bank as well as an increase in the acquisition price. Due to this combined effect, the decrease in the foreign bank's profit in case of acquisition entry is larger than the fall of the foreign bank's profit in case of greenfield entry arising from a decreasing market share only. Thus, acquisition entry is less appealing compared to greenfield entry when the screening efficiency of domestic banks increases.

When we interpret an increasing screening efficiency of host country banks as a signal for higher financial development, we can state as before that the less developed a banking market is, the more foreign banks tend to enter the market via the acquisition of a domestic bank.

\section{Size of Refinancing Costs of Host Country Banks}

We find that when refinancing costs $i_{B}$ of host country banks decrease, foreign banks must possess a relatively better screening technology in order to profitably enter a new market. In addition, cross border lending and acquisition entry lose in attractiveness. Our results are summarized in Proposition 7.

Proposition 7 When refinancing costs of host country banks decrease, foreign banks must have relatively better screening skills in order to profitably enter a new market. The ranges of cross border lending and acquisition entry contract. That is,

$$
\frac{d \delta_{A}^{C B L}}{d i_{B}}<0, \frac{d \delta_{A}^{G R}}{d i_{B}}<0, \frac{d \delta_{A}^{A C}}{d i_{B}}<0, \text { and }\left|\frac{d \delta_{A}^{C B L}}{d i_{B}}\right|>\left|\frac{d \delta_{A}^{G R}}{d i_{B}}\right|
$$

Proof: see Appendix.

The intuition for these results is as follows. When host country banks incur relatively lower refinancing costs, foreign banks lose in terms of market share. Obviously, entry becomes attractive only for relatively better screening foreign banks.

Since the effect of a falling market share is larger in case of greenfield entry compared to cross border lending due to the beforehand larger market share, greenfield entry becomes relatively less attractive compared to cross border lending when refinancing conditions of domestic banks improve.

When refinancing costs of host country banks decrease, acquisition entry becomes less attractive compared to greenfield entry. Note that the market share of the foreign bank in case 
of acquisition entry falls and, in addition, the acquisition price increases. Due to this combined effect, the fall of the profit of the foreign bank with acquisition entry is larger than the decrease of the profit in case of de novo investment originating from a declining market share only. Therefore, acquisition entry becomes less attractive compared to greenfield entry when refinancing costs of domestic banks fall.

Note that the effects of falling interest rates of domestic banks are equivalent to the impact of increasing interest rates of foreign banks. By interpreting better refinancing conditions of host country banks relative to foreign banks as a sign of increased financial development, we again conclude that in banking markets on a lower stage of development, foreign banks tend to choose cross border lending and acquisition entry when entering the host banking market.

\section{Degree of Competitive Pressure in the Host Banking Market}

We are further interested in how the degree of competition in the host banking market influences the entry mode decision of a foreign bank. The competitive pressure in the local banking market can be expressed by the inverse of transportation cost $\frac{1}{t}$. Note that the larger the transportation cost parameter $t$ and the more costly it becomes for borrowers to travel to a bank, the less intense price competition will be between banks. Conversely, the higher is $\frac{1}{t}$, the more competitive is the market environment.

We find that foreign banks must possess a relatively better screening technology in order to profitably enter highly competitive markets. Furthermore, acquisition entry loses in attractiveness in host banking markets characterized by rather intense competition. The effects on cross border lending and greenfield entry are ambiguous. Our results are stated in Proposition 8.

Proposition 8 When competitive pressure in the host banking market increases, foreign banks must be relatively better at screening borrowers in order to profitably enter a new market. For $\delta_{A}^{G R}<\widetilde{\delta}_{A}^{G R}$, the range of cross border lending contracts whereas the range of greenfield entry expands. For $\delta_{A}^{G R}>\widetilde{\delta}_{A}^{G R}$, the effect of rising competition on cross border lending and greenfield entry is ambiguous. The range of acquisition entry unambiguously contracts. That is,

$$
\begin{aligned}
& \text { (1) } \frac{d \delta_{A}^{C B L}}{d\left(\frac{1}{t}\right)}>0, \frac{d \delta_{A}^{G R}}{d\left(\frac{1}{t}\right)}<0, \frac{d \delta_{A}^{A C}}{d\left(\frac{1}{t}\right)}>0 \text { for } \delta_{A}^{G R}<\frac{15\left(F_{G R}-F_{C B L}\right)}{4 m \mu(1-\alpha)(1-\gamma)\left(1+i_{A}\right)} \equiv \widetilde{\delta}_{A}^{G R} \\
& \text { (2) } \frac{d \delta_{A}^{C B L}}{d\left(\frac{1}{t}\right)}>0, \frac{d \delta_{A}^{G R}}{d\left(\frac{1}{t}\right)}>0, \frac{d \delta_{A}^{A C}}{d\left(\frac{1}{t}\right)}>0 \text { for } \delta_{A}^{G R}>\widetilde{\delta}_{A}^{G R} .
\end{aligned}
$$

Proof: see Appendix.

The intuition behind these results is as follows. Again, we first turn to the threshold $\delta_{A}^{C B L}$. Increasing competitive pressure in the host banking market results in declining interest rates of all banks. It follows that in order for cross border lending to be profitable, the foreign bank must have access to a relatively better screening technology. 
The effect of rising competition on the threshold $\delta_{A}^{G R}$ is ambiguous. Note, beforehand, that the interest rate the foreign bank charges in case of cross border lending is higher than in case of greenfield entry. In contrast, the market share of the foreign bank in case of cross border lending is smaller compared to a de novo investment. Increasing competitive pressure leads to a fall both in interest rates and market shares. Hence, the overall effect is ambiguous. We find that for $\delta_{A}<\widetilde{\delta}_{A}^{G R}$, the interest rate effect dominates so that greenfield entry gains at the expense of cross border lending. However, for $\delta_{A}>\widetilde{\delta}_{A}^{G R}$, the market share effect is the driving factor which implies that cross border lending becomes relatively more attractive compared to greenfield entry.

We now examine the impact of an increase in competitive pressure on the attractiveness of acquisition entry. Note that an increase in competition implies lower interest rates and profits both in case of greenfield and acquisition entry. In addition, the acquisition price falls. Since, however, the fall in profit is larger in case of acquisition compared to greenfield entry, the acquisition of a domestic bank is less appealing the more intense competition is.

Note that tough competition serves as an indicator of high financial development. Falling transportation costs may reflect an increased transparency in the market as well as a higher standardization of financial products implying less pronounced preferences of borrowers for a certain type of bank. Alternatively, the introduction of new information and communication technologies in banking may lead to a fall in physical transportation costs of borrowers. We conclude as before that the less developed a host banking market is, the more foreign banks opt for entry via acquisition.

\subsection{Size of the Host Banking Market}

We now turn to the impact of the size of the host banking market measured in terms of the mass of borrowers $m$ on the entry mode choice of foreign banks. We find that the larger the host banking market, the more easily entry becomes profitable for less efficiently screening foreign banks. Furthermore, the larger the host country, the more appealing greenfield entry and the less attractive acquisition entry become. Our results are stated in Proposition 9.

Proposition 9 The larger the host banking market, the more easily entry becomes profitable for less efficiently screening foreign banks. The range of greenfield entry expands and the range of acquisition entry contracts. That is,

$$
\frac{d \delta_{A}^{C B L}}{d m}<0, \frac{d \delta_{A}^{G R}}{d m}<0, \frac{d \delta_{A}^{A C}}{d m}>0
$$

Proof: see Appendix. 
Clearly, the profit of a foreign bank operating in the host banking market via cross border lending is the higher, the larger the host banking market. It follows that in larger markets, cross border lending becomes profitable for foreign banks with relatively lower screening skills.

The larger the host banking market, the higher a foreign bank's profit both in case of cross border lending and greenfield entry is. Again, the rise in the foreign bank's profit due to an increase in the market size is more pronounced in case of greenfield entry due to the beforehand larger market share so that a de novo investment becomes more attractive compared to cross border lending.

In case of acquisition entry, a greater market size also allows the foreign bank to serve more customers, implying an increase in its profit. However, there is a countervailing effect since the acquisition price rises, too. Overall, the increase in the profit of a foreign bank in case of greenfield entry dominates the rise in profit in case of acquisition entry. Hence, the larger the host banking market, the more appealing greenfield entry compared to acquisition entry is for a foreign bank.

We can further conclude from our analysis that foreign banks tend to prefer financial foreign direct investments, i.e. de novo investments and acquisitions, over cross border lending the more, the larger the host banking market is.

\subsection{Empirical Evidence}

In this section, we showed that in less developed banking markets, foreign banks tend to opt for cross border lending and acquisition entry. In contrast, we found a tendency towards greenfield entry in banking markets on a higher level of financial development. Empirical literature related to our comparative statics analysis is scarce. Nevertheless, our result of a trend towards cross border lending in rather low developed banking markets is confirmed by García Herrero and Martínez Pería (2007). Beermann (2007) finds that greenfield entry becomes more likely compared to acquisition entry the more developed a host banking market is.

Furthermore, we investigated how the entry mode decision of foreign banks depends on the size of the host banking market. From our analysis, we concluded that foreign banks tend to prefer financial foreign direct investments, i.e. de novo investments and acquisitions, over cross border lending the larger the host banking market is. Buch and Lipponer (2007), García Herrero and Martínez Pería (2007) and Tekin-Koru (2006) all find empirical support for this outcome. We also demonstrated that the larger a host country is, the larger the acquisition price becomes and the less attractive the acquisition of a local bank is. Hence, we found that foreign banks tend to favor acquisition entry in small host banking markets and greenfield entry in larger countries. Evidence for this result is provided by Raff et al. (2006). In addition, Correa (2008) concludes that domestic banks that are located in small countries are more likely to be acquired compared to banks operating in larger countries. 


\section{Welfare Analysis and Implications for the Regulation of Foreign Bank Entry}

In this section we derive the preferred entry mode pattern of the host banking market's policy maker and compare it to the entry mode pattern favored by the foreign banks. The host country's policy maker maximizes welfare consisting of the sum of borrower rents and rents of domestic banks. Borrower rents are captured by the willingness to pay of borrowers minus the repayments of borrowers to banks and their transport costs. Bank rents comprise the revenues of banks minus their costs. Rents of foreign banks are not included in welfare.

We compare the different welfare functions in case of no entry, $W_{N E}$, cross border lending, $W_{C B L}$, greenfield entry, $W_{G R}$, and acquisition entry, $W_{A C}$, in order to derive the preferred entry mode pattern of the policy maker. The welfare functions are given in Lemma 4.

Lemma 4 The welfare functions in case of no entry, cross border lending, greenfield entry, and acquisition entry are given as follows:

$$
\begin{aligned}
W_{N E}= & m\left[\gamma\left(v-i_{B}\right)-(1-\gamma)\left(1-\delta_{B}\right)\left(1+i_{B}\right)-\frac{t}{8}\right] \\
W_{C B L}= & m\left\{\gamma v-\frac{t}{12}-\frac{1}{3} \gamma\left(\widetilde{r}_{A}^{C B L}+2 \widetilde{r}_{B}^{C B L}\right)+\frac{1}{t}\left(\gamma-\frac{1}{2}\right)\left(\widetilde{r}_{B}^{C B L}-\widetilde{r}_{A}^{C B L}\right)^{2}+\right. \\
& \left.2\left[\frac{1}{3}-\frac{1}{2 t}\left(\widetilde{r}_{B}^{C B L}-\widetilde{r}_{A}^{C B L}\right)\right]\left[\gamma\left(\widetilde{r}_{B}^{C B L}-i_{B}\right)-(1-\gamma)\left(1-\delta_{B}\right)\left(1+i_{B}\right)\right]\right\} \\
W_{G R}= & m\left\{\gamma v-\frac{t}{12}-\frac{1}{3} \gamma\left(\widetilde{r}_{A}^{G R}+2 \widetilde{r}_{B}^{G R}\right)+\frac{1}{t}\left(\gamma-\frac{1}{2}\right)\left(\widetilde{r}_{B}^{G R}-\widetilde{r}_{A}^{G R}\right)^{2}+2\left[\frac{1}{3}-\frac{1}{2 t}\left(\widetilde{r}_{B}^{G R}-\widetilde{r}_{A}^{G R}\right)\right]\right. \\
& {\left.\left[\gamma\left(\widetilde{r}_{B}^{G R}-i_{B}\right)-(1-\gamma)\left(1-\delta_{B}\right)\left(1+i_{B}\right)\right]\right\} } \\
W_{A C}= & m\left\{\gamma\left[v-\widetilde{r}_{A}^{A C}\left(\frac{1}{2}+\frac{1}{t}\left(\widetilde{r}_{B}^{A C}-\widetilde{r}_{A}^{A C}\right)\right)-\left(\frac{1}{2}-\frac{1}{t}\left(\widetilde{r}_{B}^{A C}-\widetilde{r}_{A}^{A C}\right)\right) i_{B}\right]-\right. \\
& \left(\frac{1}{2}-\frac{1}{t}\left(\widetilde{r}_{B}^{A C}-\widetilde{r}_{A}^{A C}\right)\right)(1-\gamma)\left(1-\delta_{B}\right)\left(1+i_{B}\right)-\frac{t}{2}\left[\frac{1}{4}+\frac{1}{t^{2}}\left(\widetilde{r}_{B}^{A C}-\widetilde{r}_{A}^{A C}\right)^{2}\right]+ \\
& \left.\frac{1}{25 t \gamma}\left[\frac{5}{3} t \gamma-\Delta-\mu(1-\gamma)\left(1+i_{A}\right) \delta_{A}\right]^{2}\right\}
\end{aligned}
$$

Proof: see Appendix.

By comparing the different welfare functions we arrive at the preferred entry mode pattern of the policy maker. Our results are summarized in Proposition 10.

Proposition 10 The policy maker prefers a foreign bank not to enter the market when it is rather inefficient in screening borrowers. Greenfield entry is favored for intermediate screening efficiencies of foreign banks. If a foreign bank is highly efficient in screening borrowers, the policy maker prefers it to acquire a local bank. That is, 
(1) $W_{N E}>W_{C B L}, W_{G R}, W_{A C} \quad$ for $\quad \delta_{A}<\delta_{W}^{G R}$

(2) $W_{G R}>W_{C B L}, W_{N E}, W_{A C} \quad$ for $\quad \delta_{W}^{G R}<\delta_{A}<\delta_{W}^{A C}$

(3) $W_{A C}>W_{C B L}, W_{N E}, W_{G R} \quad$ for $\quad \delta_{W}^{A C}<\delta_{A}$

with $\delta_{W}^{G R}=\frac{\frac{5}{12} t \gamma\left(\sqrt{25 \gamma^{2}-17 \gamma+3}-\gamma\right)-(3 \gamma-1) \Delta}{\mu(1-\gamma)(3 \gamma-1)\left(1+i_{A}\right)}$ and $\delta_{W}^{A C}=x_{A C}^{W}+\frac{5 \sqrt{X_{A C}^{W}}}{2(1-\gamma)\left(1+i_{A}\right)\left[25(4 \gamma-1)-18 \mu^{2}(5 \gamma-2)\right]}$,

$x_{A C}^{W}=\frac{\left[\frac{15}{2} t \gamma(6 \mu-5) \gamma-[25(4 \gamma-1)-18 \mu(5 \gamma-2)] \Delta\right]}{(1-\gamma)\left(1+i_{A}\right)\left[25(4 \gamma-1)-18 \mu^{2}(5 \gamma-2)\right]}$,

$X_{A C}^{W}=t \gamma^{2}\left\{t\left[25\left(10 \gamma+17 \gamma^{2}-3\right)+18 \mu\left(6 \mu-30 \gamma^{2}-11 \gamma \mu+8 \gamma^{2} \mu\right)\right]+\right.$ $72(1-\mu)[5 \gamma(4-3 \mu)+6 \mu-5] \Delta\}+72(1-\mu)^{2}(4 \gamma-1)(5 \gamma-2) \Delta^{2}$.

Proof: see Appendix.

Note, beforehand, that cross border lending is strictly dominated by greenfield entry. This result is mainly driven by the fact that interest rates of foreign banks are lower in case of greenfield entry than cross border lending due to the better knowledge of the market which benefits local borrowers.

The intuition of our results mainly rests on the impact of the foreign bank's screening ability on, first, the payments of borrowers to foreign banks and, second, costs of domestic banks. Note that the payments of borrowers to foreign banks are zero in case of no entry, of intermediate size in case of greenfield entry, and largest in case of acquisition entry. In contrast, the costs of domestic banks vary with market shares and are highest in case of no entry, lower if foreign banks enter via de novo investment, and smallest with acquisition entry.

Obviously, if no foreign bank enters the market, an increasing screening efficiency of the foreign bank has no impact on the payments of borrowers to foreign banks and costs of domestic banks. Yet, in case of greenfield entry, an increase in the quality of the foreign bank's screening technology drives down the interest rates foreign banks ask as well as the costs of domestic banks due to falling market shares. Hence, as soon as the screening ability of the foreign bank is larger than the threshold $\delta_{W}^{G R}$, greenfield entry is preferred to no entry by the policy maker. Moreover, the negative effect of an increasing screening efficiency of the foreign bank on interest rates asked by foreign banks and costs of domestic banks is even larger in case of acquisition entry. Thus, for a screening ability of the foreign bank larger than $\delta_{W}^{A C}$, the policy maker favors acquisition over greenfield entry. We show in the Appendix that $\delta_{W}^{G R}<\delta_{W}^{A C}$ holds (see proof of Proposition 10).

Before we turn to how the regulation of foreign bank entry is shaped, let us explain that the policy maker may face difficulties when trying to enforce greenfield entry. Greenfield entry is profitable for foreign banks if $\pi_{A}^{G R} \geq 0$ holds which is equivalent to $\delta_{A} \geq \widehat{\delta}_{A}^{G R}$ (see proof of Proposition 11). If $\widehat{\delta}_{A}^{G R}>\delta_{W}^{G R}$ holds, de novo investment is not profitable for foreign banks with 
screening abilities in the range $\delta_{W}^{G R} \leq \delta_{A}<\widehat{\delta}_{A}^{G R}$. Hence, for this parameter range, greenfield entry cannot be implemented by the policy maker. ${ }^{11}$

However, acquisition entry can be enforced whenever the policy maker prefers this entry mode. We show in the Appendix that $\delta_{W}^{A C}>\delta_{A}^{A C}$ holds (see proof of Proposition 11). Clearly, for $\delta_{A} \geq \delta_{A}^{A C}$, foreign banks make profits by entering via acquisition entry as $\delta_{A}^{A C}$ constitutes the threshold for which foreign banks prefer acquisition entry over all other entry modes. Hence, no difficulties arise for the policy maker to enforce entry via acquisition since $\delta_{W}^{A C}>\delta_{A}^{A C}$.

Let us now look in more detail at the regulation of foreign bank entry. Although - apart from cross border lending - the policy maker's preferred entry mode pattern is similar to the one favored by the foreign banks, our model still provides interesting implications concerning the regulation of foreign bank entry. Our results from the comparison of the threshold values $\delta_{W}^{G R}$ and $\delta_{W}^{A C}$ that determine the policy maker's preferred entry mode pattern and the thresholds $\delta_{A}^{C B L}, \delta_{A}^{G R}$, and $\delta_{A}^{A C}$ defining the entry mode pattern preferred by the foreign banks as derived in section 4 are given in Proposition 11.

Proposition 11 Entry is permitted but to foreign banks that rather efficiently screen borrowers. The more competitive the host market environment is, the lower the requirements concerning a foreign bank's screening efficiency for entry are set. Cross border lending is not allowed for. Moreover, only the most efficiently screening foreign banks are allowed to acquire a domestic bank. Foreign banks that wish to grant cross border loans or acquire a local bank are forced to enter via de novo investment if their screening skills are insufficiently low. That is,

(1) $\delta_{A}^{C B L}<\widehat{\delta}_{A}^{G R}<\delta_{W}^{G R}$

(2) $\delta_{A}^{A C}<\delta_{W}^{A C}$

(3) $\frac{d \delta_{W}^{G R}}{d\left(\frac{1}{t}\right)}<0$

Proof: see Appendix.

Consider Figure 1 for our explanations. Three locations are possible for the threshold $\delta_{W}^{G R}$ as is shown in the three different scenarios. Note that the more competitive the host market environment is, the more $\delta_{W}^{G R}$ shifts to the left and the lower the policy maker sets the requirements concerning a foreign bank's screening efficiency for entry.

Let us first look at foreign banks that wish to grant cross border loans. In scenario (1), foreign banks with efficiency level $\delta_{A}^{C B L} \leq \delta_{A}<\delta_{W}^{G R}$ are denied entry whereas foreign banks with efficiency $\delta_{W}^{G R} \leq \delta_{A}<\delta_{A}^{G R}$ are forced to enter via de novo investment instead of cross

\footnotetext{
${ }^{11}$ In principle, the policy maker could also make a payment to the foreign bank in order to induce it to enter the market compensating for the loss of the foreign bank from operating in the host country. Then, greenfield entry could take place within the range $\delta_{W}^{G R} \leq \delta_{A}<\widehat{\delta}_{A}^{G R}$. However, note that $\delta_{W}^{G R}$ will move a little to the right since the payments to the foreign bank let the welfare function shift downwards. Since our qualitative results do not change, we abstract from payments to foreign banks.
} 
border lending. Both in scenario (2) and (3), all foreign banks that want to operate via cross border lending are denied entry.

Second, consider foreign banks that favor entry via de novo investment. Depending on the location of $\delta_{W}^{G R}$, these banks may either enter via their preferred entry mode in scenario (1) or be denied entry in scenario (3). In scenario (2), banks with a screening efficiency in the range of $\delta_{A}^{G R} \leq \delta_{A}<\delta_{W}^{G R}$ are not granted an entry permit whereas banks with screening efficiency $\delta_{W}^{G R} \leq \delta_{A}<\delta_{A}^{A C}$ are allowed to enter via de novo investment.

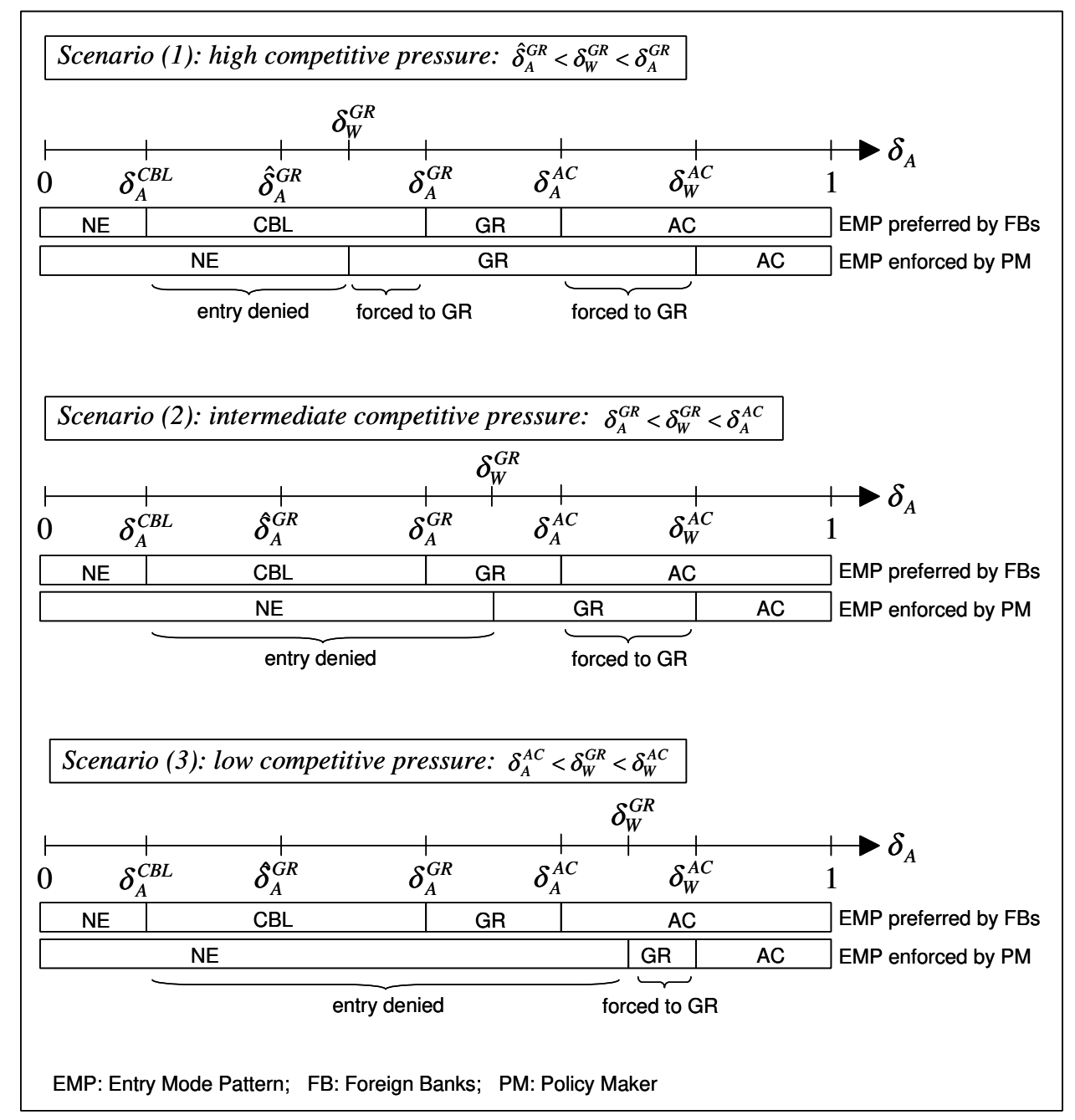

Figure 1: Regulation of Foreign Bank Entry

Finally, let us examine the situation of foreign banks that prefer to acquire a domestic bank. Foreign banks with a screening efficiency larger than $\delta_{W}^{A C}$ are in all three scenarios allowed to acquire a local bank. In scenario (1) and (2), banks with screening efficiency $\delta_{A}^{A C} \leq \delta_{A}<\delta_{W}^{A C}$ are forced to enter via de novo investment. In scenario (3), banks with a screening efficiency in the range $\delta_{A}^{A C} \leq \delta_{A}<\delta_{W}^{G R}$ are denied entry and banks with a screening efficiency in the range $\delta_{W}^{G R} \leq \delta_{A}<\delta_{W}^{A C}$ are forced to enter via de novo investment. 
Hence, the regulation of foreign bank entry is shaped as follows. Entry is permitted but to foreign banks that rather efficiently screen borrowers. The more competitive the host market environment is, the lower the policy maker sets the requirements concerning a foreign bank's screening efficiency for entry. Hence, the less competitive the market environment is, the more likely it is that foreign banks are denied entry. The policy maker does not allow for cross border lending. Moreover, regulators grant a permit to acquire a domestic bank only to the most efficiently screening foreign banks. Foreign banks that intend to expand via cross border lending or the acquisition of a local bank are forced to enter via de novo investment if their screening skills are insufficiently low.

Note that although the policy maker may not perfectly observe the screening efficiency of a foreign bank, the quality of its screening technology may be proxied by the size of loan loss provisions or the rating of the bank. Moreover, as has been found by Berger (2007) and Köhler (2008), the regulation of acquisition entry not only takes place explicitly via restrictions on ownership shares but also implicitly via, for instance, the delay of licensing procedures.

García Herrero and Martínez Pería (2007) provide support for our finding that cross border lending is least liked by the policy maker of the host country. However, their argument is somewhat different. They suggest that cross border lending implies a greater volatility in capital flows and is therefore often impeded by taxes or capital controls on foreign loans. Peek and Rosengren (2000) point to the problem that cross border lending is more difficult for the host country supervisors to monitor or influence.

Although a large part of foreign bank entry into Latin American and transition countries occurred via the acquisition of domestic banks, this was often due to the need to recapitalize domestic banks in the aftermath of banking crises in Latin America (Martínez Pería and Mody, 2004) as well as due to large privatization programs in transition economies (Vo Thi and Vencappa, 2007). In fact, the literature generally points to the extensive regulation of acquisition compared to greenfield entry. Examples are Berger et al. (2008), Majnoni et al. (2003), and Peek and Rosengren (2000).

\section{Empirical Hypotheses}

Our model gives rise to several testable hypotheses concerning both the entry mode decision of multinational banks and the regulation of foreign bank entry. We state our first hypothesis with respect to the entry mode pattern favored by foreign banks.

Hypothesis 1 In a given banking market, banks with the lowest screening efficiencies do not expand abroad. With increasing efficiency, banks grant cross border loans. Still more efficient 
banks opt for de novo investment. The most efficient banks choose to access a new market via the acquisition of a local bank.

We further analyzed how the multinational banks' entry mode choice is affected by the financial development of host countries. Based on our results, we formulate our second testable prediction.

Hypothesis 2 The less developed a host banking market is, the wider the range of foreign banks that opt for cross border lending and acquisition entry. In more developed banking markets a trend towards de novo investment exists.

Our findings concerning the impact of the size of host countries on the entry mode choice of foreign banks gives rise to our third hypothesis.

Hypothesis 3 The larger a host banking market is, the wider the range of foreign banks that expand via a financial foreign direct investment compared to cross border lending. More specifically, foreign banks tend to favor the acquisition of a domestic bank when they enter rather small countries and de novo investment when they commence to operate in rather large banking markets.

We formulate our last testable prediction with respect to our findings regarding the regulation of foreign bank entry.

Hypothesis 4 Foreign banks present in a given host banking market are rather efficient in screening borrowers. The more competitive the market environment, the lower the requirements concerning a foreign bank's screening efficiency for entry are and, accordingly, the lower the average screening efficiency of foreign banks is expected to be. Cross border lending tends to be most strictly regulated. The most efficient foreign banks in the market tend to be those that have acquired a domestic bank.

A test of our first three hypotheses requires data on the home markets of multinational banks. Only then one can account for a certain range of banks actually not expanding abroad. With respect to our second and third hypothesis, additional information on the financial development and the size of the host markets of multinational banks are needed. Moreover, a test of our first three hypotheses should be based on rather little regulated host banking markets. Clearly, a test of our last prediction requires data on host countries of foreign banks where regulation of foreign bank entry indeed takes places.

Throughout the empirical analysis, the screening efficiency of foreign and host country banks could be proxied by the size of loan loss provisions or the rating of a bank. Soft information problems may be captured by the physical, cultural, legal or economic distance between foreign and host banking markets. The soft information variable needs to be interacted with a dummy variable that captures entry via cross border lending or greenfield investment on the one hand 
and acquisition of a domestic bank on the other hand. Competitive pressure may be proxied by the degree of product differentiation or by the degree of transparency in the banking market.

\section{Conclusions}

In this paper, we analyzed a foreign bank's trade-off between cross border lending and a financial foreign direct investment, i.e. greenfield or acquisition entry. We showed that if foreign banks are rather inefficient in screening borrowers, they choose not to expand abroad. With increasing efficiency, banks grant cross border loans. Still more efficient banks opt for de novo investment whereas the most efficient banks favor the acquisition of a local bank.

Moreover, we investigated how the entry mode choice of foreign banks is affected by the host country's development and size. We found that the less developed a banking market is, the wider the range of foreign banks that opt for cross border lending and acquisition entry and the smaller the range of foreign banks that expand via de novo investment. Moreover, the smaller the host banking market, the larger the range of foreign banks that prefer the acquisition of a domestic bank and the smaller the range of foreign banks that favor greenfield entry.

Finally, we studied the regulation of foreign bank entry. We showed that entry is permitted but to foreign banks that rather efficiently screen borrowers. Furthermore, the less competitive the market environment is, the more likely it is that foreign banks are denied entry. Cross border lending is not allowed for. Foreign banks that intend to expand via cross border lending or the acquisition of a local bank are forced to enter via de novo investment if their screening efficiency is insufficiently low.

Our model set-up allows for several interesting extensions. First, we might not only consider the influence of the host country's development but also the impact of the development of a foreign bank's home country on its entry mode choice. If we interpret a foreign bank's screening efficiency as an indicator of its home market's development, our model implies the following results. Banks based in the most developed countries would tend to expand via acquisitions. Banks from less developed countries would opt for de novo investment. Banks based in still less developed countries would prefer to grant cross border loans whereas banks located in the least developed countries would not expand abroad.

Furthermore, it would be interesting to allow for asymmetries in domestic banks. If local banks differed in their screening abilities, the incentives of foreign banks to acquire a domestic bank would depend on a trade-off as follows. A lower efficiency would imply a smaller acquisition price. However, costs related to restructuring processes or the amortization of bad credits might be much higher for less efficient local banks. 


\section{Appendix}

\section{Proof of Lemma 1:}

The marginal borrower between bank $A$ and $B_{1}$ and bank $A$ and $B_{2}$ is given by

$x_{A, B_{1}}^{C B L}=\frac{1}{6}+\frac{r_{B_{1}}^{C B L}-r_{A}^{C B L}}{2 t}$ and $x_{A, B_{2}}^{C B L}=\frac{1}{6}+\frac{r_{B_{2}}^{C B L}-r_{A}^{C B L}}{2 t}$.

It follows that the market share of banks can be expressed by $m \phi_{A}^{C B L}, m \phi_{B_{1}}^{C B L}$ and $m \phi_{B_{2}}^{C B L}$ with $\phi_{A}^{C B L} \equiv \frac{1}{3}+\frac{r_{B_{1}}^{C B L}+r_{B_{2}}^{C B L}-2 r_{A}^{C B L}}{2 t}, \phi_{B_{1}}^{C B L} \equiv \frac{1}{3}+\frac{r_{A}^{C B L}+r_{B_{2}}^{C B L}-2 r_{B_{1}}^{C B L}}{2 t}$ and $\phi_{B_{2}}^{C B L} \equiv \frac{1}{3}+\frac{r_{A}^{C B L}+r_{B_{1}}^{C B L}-2 r_{B_{2}}^{C B L}}{2 t}$.

Hence, banks' profit functions are given by

$\pi_{A}^{C B L}=\left[\gamma\left(r_{A}^{C B L}-i_{A}\right)-(1-\gamma)\left(1-\alpha \mu \delta_{A}\right)\left(1+i_{A}\right)\right] m \phi_{A}^{C B L}-F_{C B L}$

$\pi_{B_{j}}^{C B L}=\left[\gamma\left(r_{B_{j}}^{C B L}-i_{B}\right)-(1-\gamma)\left(1-\delta_{B}\right)\left(1+i_{B}\right)\right] m \phi_{B_{j}}^{C B L}$.

$\frac{d \pi_{A}^{C B L}}{d r_{A}^{C B B}} \stackrel{!}{=} 0, \frac{d \pi_{B_{1}}^{C B L}}{d r_{B_{1}}^{C B L}} \stackrel{!}{=} 0$, and $\frac{d \pi_{B_{2}}^{C B L}}{d r_{B_{2}}^{C B L}} \stackrel{!}{=} 0$ implies

$\widetilde{r}_{A}^{C B L}=\frac{1}{5 \gamma}\left\{\frac{5}{3} t \gamma+2 i_{B}+3 i_{A}+(1-\gamma)\left[5-2 \delta_{B}\left(1+i_{B}\right)-3 \alpha \mu \delta_{A}\left(1+i_{A}\right)\right]\right\}$

$\widetilde{r}_{B_{1}}^{C B L}=r_{B_{2}}^{C B L}=\frac{1}{5 \gamma}\left\{\frac{5}{3} t \gamma+4 i_{B}+i_{A}+(1-\gamma)\left[5-4 \delta_{B}\left(1+i_{B}\right)-\alpha \mu \delta_{A}\left(1+i_{A}\right)\right]\right\} \equiv r_{B}^{C B L}$

$\pi_{A}^{C B L}=m t \gamma\left(\widetilde{\phi}_{A}^{C B L}\right)^{2}-F_{C B L}$ and $\pi_{B_{1}}^{C B L}=\pi_{B_{2}}^{C B L}=m t \gamma\left(\widetilde{\phi}_{B}^{C B L}\right)^{2} \equiv \pi_{B}^{C B L}$

with market shares $\widetilde{\phi}_{A}^{C B L} \equiv \frac{2}{5 t \gamma}\left[\frac{5}{6} t \gamma+\Delta+\alpha \mu(1-\gamma)\left(1+i_{A}\right) \delta_{A}\right]$ and $\widetilde{\phi}_{B_{1}}^{C B L}=\widetilde{\phi}_{B_{2}}^{C B L}=\frac{1}{5 t \gamma}\left[\frac{5}{3} t \gamma-\right.$ $\left.\Delta-\alpha \mu(1-\gamma)\left(1+i_{A}\right) \delta_{A}\right] \equiv \widetilde{\phi}_{B}^{C B L}$ and $\Delta \equiv i_{B}-i_{A}-(1-\gamma)\left(1+i_{B}\right) \delta_{B}$.

\section{Proof of Proposition 1:}

Note that $\frac{d \pi_{A}^{C B L}}{d \delta_{A}}=\frac{4 m \alpha \mu(1-\gamma)\left(1+i_{A}\right)}{5} \widetilde{\phi}_{A}^{C B L}>0$ and $\frac{d^{2} \pi_{A}^{C B L}}{d \delta_{A}^{2}}=\frac{2 m}{t \gamma}\left[\frac{2}{5} \alpha \mu(1-\gamma)\left(1+i_{A}\right)\right]^{2}>0$ so that $\pi_{A}^{C B L}$ is increasing and convex in $\delta_{A}$. Cross border lending is feasible for bank $A$ if $\pi_{A}^{C B L} \geq 0$. Solving for bank $A$ 's screening ability yields $\delta_{A} \geq \frac{\frac{5}{\frac{5}{\frac{t \gamma F_{C B L}}{m}}}-\Delta-\frac{5}{6} t \gamma}{\alpha \mu(1-\gamma)\left(1+i_{A}\right)} \equiv \delta_{A}^{C B L}$.

Note that since $\pi_{A}^{C B L}$ is increasing and convex in $\delta_{A}$ it follows that $\underset{\delta_{A} \in \mathbb{R}}{\arg \min }\left\{\pi_{A}^{C B L}\right\}=-\frac{\frac{5}{6} t \gamma+\Delta}{\alpha \mu(1-\gamma)\left(1+i_{A}\right)}<$ 0. Hence, $\frac{5}{6} t \gamma+\Delta>0$ must hold. We will refer to this condition as Condition (1): $\frac{5}{6} t \gamma+\Delta>0$.

\section{Proof of Lemma 2:}

Analogous to Proof of Lemma 1 we arrive at

$$
\begin{aligned}
& \widetilde{r}_{A}^{G R}=\frac{1}{5 \gamma}\left\{\frac{5}{3} t \gamma+2 i_{B}+3 i_{A}+(1-\gamma)\left[5-2 \delta_{B}\left(1+i_{B}\right)-3 \mu \delta_{A}\left(1+i_{A}\right)\right]\right\}, \\
& \widetilde{r}_{B_{1}}^{G R}=r_{B_{2}}^{G R}=\frac{1}{5 \gamma}\left\{\frac{5}{3} t \gamma+4 i_{B}+i_{A}+(1-\gamma)\left[5-4 \delta_{B}\left(1+i_{B}\right)-\mu \delta_{A}\left(1+i_{A}\right)\right]\right\} \equiv r_{B}^{G R}, \\
& \pi_{A}^{G R}=m t \gamma\left(\widetilde{\phi}_{A}^{G R}\right)^{2}-F_{G R} \text { and } \pi_{B_{1}}^{G R}=\pi_{B_{2}}^{G R}=m t \gamma\left(\widetilde{\phi}_{B}^{G R}\right)^{2} \equiv \pi_{B}^{G R} .
\end{aligned}
$$




\section{Proof of Proposition 2:}

Note that $\frac{d \pi_{A}^{G R}}{d \delta_{A}}=\frac{4 m \mu(1-\gamma)\left(1+i_{A}\right)}{5} \widetilde{\phi}_{A}^{G R}>0$ and $\frac{d^{2} \pi_{A}^{G R}}{d \delta_{A}^{2}}=\frac{2 m}{t \gamma}\left[\frac{2}{5} \mu(1-\gamma)\left(1+i_{A}\right)\right]^{2}>0$. Further, due to $\widetilde{\phi}_{B}^{G R}>\widetilde{\phi}_{B}^{C B L}$ and $0<\alpha<1$ it holds that $\frac{d \pi_{A}^{G R}}{d \delta_{A}}>\frac{d \pi_{A}^{C B L}}{d \delta_{A}}$ and $\frac{d^{2} \pi_{A}^{G R}}{d \delta_{A}^{2}}>\frac{d^{2} \pi_{A}^{C B L}}{d \delta_{A}^{2}}$. Since it also holds that $\left.\pi_{A}^{C B L}\right|_{\delta_{A}=0}=m t \gamma\left\{\frac{2}{5 t \gamma}\left[\frac{5}{6} t \gamma+\left(i_{B}-i_{A}\right)\right]\right\}^{2}-F_{C B L}>\left.\pi_{A}^{G R}\right|_{\delta_{A}=0}=m t \gamma\left\{\frac{2}{5 t \gamma}\left[\frac{5}{6} t \gamma+\right.\right.$ $\left.\left.\left(i_{B}-i_{A}\right)\right]\right\}^{2}-F_{G R}$ due to $F_{G R}>F_{C B L}$, it follows that only one intersection between $\pi_{A}^{G R}$ and $\pi_{A}^{C B L}$ is possible for $\delta_{A}>0$. Greenfield entry is feasible for bank $A$ in case of $\pi_{A}^{G R} \geq \pi_{A}^{C B L}$. Solving for bank $A$ 's screening ability yields

$\delta_{A} \geq \frac{\sqrt{X_{G R}}-\Delta-\frac{5}{6} t \gamma}{\mu(1+\alpha)(1-\gamma)\left(1+i_{A}\right)} \equiv \delta_{A}^{G R}$ with $X_{G R} \equiv\left(\Delta+\frac{5}{6} t \gamma\right)^{2}+\frac{25 t \gamma(1+\alpha)\left(F_{G R}-F_{C B L}\right)}{4 m(1-\alpha)}$.

\section{Proof of Lemma 3:}

Analogous to Proof of Lemma 1 we arrive at

$\widetilde{r}_{A}^{A C}=\frac{1}{3 \gamma}\left\{\frac{3}{2} t \gamma+i_{B}+2 i_{A}+(1-\gamma)\left[3-\delta_{B}\left(1+i_{B}\right)-2 \delta_{A}\left(1+i_{A}\right)\right]\right\}$,

$\widetilde{r}_{B}^{A C}=\frac{1}{3 \gamma}\left\{\frac{3}{2} t \gamma+2 i_{B}+i_{A}+(1-\gamma)\left[3-2 \delta_{B}\left(1+i_{B}\right)-\delta_{A}\left(1+i_{A}\right)\right]\right\}$,

$\pi_{A}^{A C}=m t \gamma\left\{\left(\widetilde{\phi}_{A}^{A C}\right)^{2}\right\}-P_{A C}-F_{A C}$ and $\pi_{B}^{A C}=m t \gamma\left(\widetilde{\phi}_{B}^{A C}\right)^{2}$.

\section{Proof of Proposition 3:}

Derivation of Domestic Banks' Profits with no Foreign Bank Entry

Analogous to Proof of Lemma 1 we arrive at

$\widetilde{r}_{B_{1}}^{N E}=\widetilde{r}_{B_{2}}^{N E}=\frac{1}{2 \gamma}\left[t \gamma+2 i_{B}+2\left(1-\delta_{B}\left(1+i_{B}\right)\right)(1-\gamma)\right] \equiv \widetilde{r}_{B}^{N E}$ and $\pi_{B_{1}}^{N E}=\pi_{B_{2}}^{N E}=\frac{m t \gamma}{4} \equiv \pi_{B}^{N E}$.

Derivation of $\delta_{A}^{A C}$

Note, first, that it is useful to show that (1) $\frac{d \pi_{A}^{A C}}{d \delta_{A}}>\frac{d \pi_{A}^{C B L}}{d \delta_{A}}$ in the range of $\delta_{A}^{C B L} \leq \delta_{A}<\delta_{A}^{G R}$ and (2) $\frac{d \pi_{A}^{A C}}{d \delta_{A}}>\frac{d \pi_{A}^{G R}}{d \delta_{A}}$ in the range of $\delta_{A}^{G R} \leq \delta_{A}<1$ :

(1) proof of $\frac{d \pi_{A}^{A C}}{d \delta_{A}}>\frac{d \pi_{A}^{C B L}}{d \delta_{A}}$ for $\delta_{A}^{C B L} \leq \delta_{A}<\delta_{A}^{G R}$

Note that $\frac{d \pi_{A}^{A C}}{d \delta_{A}}=2 m(1-\gamma)\left(1+i_{A}\right)\left(\frac{1}{3} \widetilde{\phi}_{A}^{A C}+\frac{1}{5} \alpha \mu \widetilde{\phi}_{B}^{C B L}\right)>0$ and $\frac{d^{2} \pi_{A}^{A C}}{d \delta_{A}^{2}}=2 \frac{m}{t \gamma}(1-\gamma)^{2}(1+$ $\left.i_{A}\right)^{2}\left(\frac{1}{9}-\frac{1}{25} \alpha^{2} \mu^{2}\right)>0$. Note also, beforehand, that by abstracting from exit of domestic banks, $\widetilde{\phi}_{A}^{G R} \leq \frac{2}{3}$ must hold due to the symmetric location of banks on the Salop circle. $\widetilde{\phi}_{A}^{G R} \leq \frac{2}{3}$ is equivalent to $\frac{5}{6} t \gamma-\Delta-\mu(1-\gamma)\left(1+i_{A}\right) \delta_{A} \geq 0$. We will use this condition further on and refer to it as Condition (2): $\frac{5}{6} t \gamma-\Delta-\mu(1-\gamma)\left(1+i_{A}\right) \delta_{A} \geq 0$. From Condition (2) follows a further useful condition which we will refer to as Condition (3): $\frac{5}{6} t \gamma-\Delta>0$.

Note that $\frac{d \pi_{A}^{A C}}{d \delta_{A}}>\frac{d \pi_{A}^{C B L}}{d \delta_{A}}$ is equivalent to $\frac{5}{6} t \gamma-\frac{5(9 \alpha \mu-5)}{9(5-2 \alpha \mu)} \Delta-\frac{5\left(9 \alpha^{2} \mu^{2}-5\right)}{9(5-2 \alpha \mu)}(1-\gamma)\left(1+i_{A}\right) \delta_{A}>0$ which is fulfilled due to Condition (2) since numerical simulations show that $-1<\frac{5(9 \alpha \mu-5)}{9(5-2 \alpha \mu)}<1$ and $\frac{5\left(9 \alpha^{2} \mu^{2}-5\right)}{9(5-2 \alpha \mu)}<\mu$. Hence, $\pi_{A}^{A C}$ and $\pi_{A}^{C B L}$ may intersect only once. 
(2) proof of $\frac{d \pi_{A}^{A C}}{d \delta_{A}}>\frac{d \pi_{A}^{G R}}{d \delta_{A}}$ for $\delta_{A}^{G R} \leq \delta_{A}<1$

Note that $\frac{d \pi_{A}^{A C}}{d \delta_{A}}=2 m(1-\gamma)\left(1+i_{A}\right)\left[\frac{1}{3} \widetilde{\phi}_{A}^{A C}+\frac{\mu}{5} \widetilde{\phi}_{B}^{G R}\right]>0$ and $\frac{d^{2} \pi_{A}^{A C}}{d \delta_{A}^{2}}=\frac{2 m}{t \gamma}(1-\gamma)^{2}\left(1+i_{A}\right)^{2}$ $\left(\frac{1}{9}-\frac{\mu^{2}}{25}\right)>0$. $\frac{d \pi_{A}^{A C}}{d \delta_{A}}>\frac{d \pi_{A}^{G R}}{d \delta_{A}}$ is equivalent to $\frac{9}{8} t \gamma-\Delta-\frac{9 \mu-5}{4}(1-\gamma)\left(1+i_{A}\right) \delta_{A}>0$ which is fulfilled due to Condition (2) as $\frac{9 \mu-5}{4}<\mu$. Hence, $\pi_{A}^{A C}$ and $\pi_{A}^{G R}$ may intersect only once.

As a consequence, $\pi_{A}^{A C}$ is increasing in $\delta_{A}$ and jumps upwards twice due to the changing acquisition prices at $\delta_{A}^{C B L}$ and $\delta_{A}^{G R}$. Since, according to the above calculations, $\pi_{A}^{A C}$ is steeper than both $\pi_{A}^{C B L}$ and $\pi_{A}^{G R}$, in principle, four possible locations exist for $\pi_{A}^{A C}$. First, $\pi_{A}^{A C}$ could lie above $\pi_{A}^{C B L}$ and $\pi_{A}^{G R}$, thus eliminating cross border lending and greenfield entry from the entry mode pattern. Second, $\pi_{A}^{A C}$ could intersect with $\pi_{A}^{C B L}$ which would exclude greenfield entry from the entry mode pattern. Third, and most interesting for us, $\pi_{A}^{A C}$ could intersect with $\pi_{A}^{G R}$, allowing for the richest possible entry mode pattern. Fourth, $\pi_{A}^{A C}$ may be located below $\pi_{A}^{C B L}$ and $\pi_{A}^{G R}$, thus excluding acquisition entry from the entry mode pattern.

Since we concentrate throughout our analysis on the richest possible entry mode pattern, bank $A$ chooses acquisition entry for $\pi_{A}^{A C} \geq \pi_{A}^{G R}$. Solving for bank $A$ 's screening ability yields $\delta_{A} \geq \frac{3 t \gamma(5-2 \mu)-2 \Delta(9 \mu-5)}{2\left(9 \mu^{2}-5\right)(1-\gamma)\left(1+i_{A}\right)}\left(1-\sqrt{X_{A C}}\right) \equiv \delta_{A}^{A C}$ with $X_{A C} \equiv 1+\frac{\left(9 \mu^{2}-5\right)\left[\left(5 t^{2} \gamma^{2}+36 t \gamma \Delta-16 \Delta^{2}\right)+\frac{180 t \gamma}{m}\left(F_{G R}-F_{A C}\right)\right]}{(3 t \gamma(5-2 \mu)-2 \Delta(9 \mu-5))^{2}}$.

\section{Proof of Proposition 5:}

$$
\begin{aligned}
\frac{d \delta_{A}^{C B L}}{d \mu}= & -\frac{1}{\mu} \delta_{A}^{C B L}<0 \text { and } \frac{d \delta_{A}^{G R}}{d \mu}=-\frac{1}{\mu} \delta_{A}^{G R}<0 .\left|\frac{d \delta_{A}^{C B L}}{d \mu}\right|<\left|\frac{d \delta_{A}^{G R}}{d \mu}\right| \text { holds as } \delta_{A}^{C B L}<\delta_{A}^{G R} . \\
\frac{d \delta_{A}^{A C}}{d \mu}= & -\frac{9\left[\left(9 \mu^{2}-5\right)\left(\frac{1}{3} t \gamma+\Delta\right)+45 \mu \lambda\right]\left(1-\sqrt{X_{A C}}\right)}{(1-\gamma)\left(1+i_{A}\right)\left(9 \mu^{2}-5\right)^{2}}- \\
& \frac{9\left[45 \mu \lambda+2\left(9 \mu^{2}-5\right)\left(\frac{1}{3} t \gamma+\Delta\right)\right]}{2(1-\gamma)\left(1+i_{A}\right) \sqrt{X_{A C}}\left(9 \mu^{2}-5\right)^{2}} \frac{\left(9 \mu^{2}-5\right)\left[\left(5 t^{2} \gamma^{2}+36 t \gamma \Delta-16 \Delta^{2}\right)+\frac{180 t \gamma}{m}\left(F_{G R}-F_{A C}\right)\right]}{(3 t \gamma(5-2 \mu)-2 \Delta(9 \mu-5))^{2}}
\end{aligned}
$$

with $\lambda \equiv \frac{1}{45}[3 t \gamma(5-2 \mu)-2 \Delta(9 \mu-5)]$.

Since $\frac{\left(9 \mu^{2}-5\right)\left[\left(5 t^{2} \gamma^{2}+36 t \gamma \Delta-16 \Delta^{2}\right)+\frac{180 t \gamma}{m}\left(F_{G R}-F_{A C}\right)\right]}{(3 t \gamma(5-2 \mu)-2 \Delta(9 \mu-5))^{2}}=X_{A C}-1=\left(\sqrt{X_{A C}}-1\right)\left(\sqrt{X_{A C}}+1\right)$, it follows

$$
\begin{aligned}
\frac{d \delta_{A}^{A C}}{d \mu}= & \frac{3 t \gamma(5-2 \mu)-2 \Delta(9 \mu-5)}{2\left(9 \mu^{2}-5\right)(1-\gamma)\left(1+i_{A}\right)}\left(1-\sqrt{X_{A C}}\right) \frac{2}{5 \lambda \sqrt{X_{A C}}} \\
& {\left[\frac{3 t \gamma(5-2 \mu)-2 \Delta(9 \mu-5)}{2\left(9 \mu^{2}-5\right)(1-\gamma)\left(1+i_{A}\right)}\left(1-\sqrt{X_{A C}}\right) \mu(1-\gamma)\left(1+i_{A}\right)+\left(\frac{1}{3} t \gamma+\Delta\right)\right] . }
\end{aligned}
$$

Due to $\frac{3 t \gamma(5-2 \mu)-2 \Delta(9 \mu-5)}{2\left(9 \mu^{2}-5\right)(1-\gamma)\left(1+i_{A}\right)}\left(1-\sqrt{X_{A C}}\right)=\delta_{A}^{A C}$, this expression can be written as

$$
\frac{d \delta_{A}^{A C}}{d \mu}=\frac{4 \delta_{A}^{A C}}{25 \lambda \sqrt{X_{A C}}}\left\{\frac{5}{6} t \gamma+\Delta+\frac{3}{2}\left[\Delta+\frac{5}{3} \mu(1-\gamma)\left(1+i_{A}\right) \delta_{A}^{A C}\right]\right\}
$$

Note, first, that $\frac{5}{6} t \gamma+\Delta>0$ due to Condition (1). Second, as we assume $\delta_{A}>\delta_{B}$ it must hold that $\widetilde{\phi}_{B}^{A C}=\frac{1}{3 t \gamma}\left[\frac{3}{2} t \gamma-\Delta-(1-\gamma)\left(1+i_{A}\right) \delta_{A}\right]<\frac{1}{2}$. This is equivalent to $\Delta+(1-\gamma)\left(1+i_{A}\right) \delta_{A}>$ 0 . By assuming $\frac{5}{3} \mu \geq 1$, or, respectively, $\mu \geq 0.6$, we have that $\frac{3}{2}\left[\Delta+\frac{5}{3} \mu(1-\gamma)\left(1+i_{A}\right) \delta_{A}^{A C}\right] \geq$ 
$0 .{ }^{12}$ Third, $\lambda=\frac{1}{45}[3 t \gamma(5-2 \mu)-2 \Delta(9 \mu-5)]>0$ is equivalent to $\frac{5}{6} t \gamma-\frac{5(9 \mu-5)}{9(5-2 \mu)} \Delta>0$ which holds due to Condition (3) since $0<\frac{5(9 \mu-5)}{9(5-2 \mu)}<1$. Hence, it holds that $\frac{d \delta_{A}^{A C}}{d \mu}>0$.

\section{Proof of Proposition 6:}

$$
\begin{aligned}
\frac{d \delta_{A}^{C B L}}{d \delta_{B}}= & \frac{1+i_{B}}{\alpha \mu\left(1+i_{A}\right)}>0 \text { and } \frac{d \delta_{A}^{G R}}{d \delta_{B}}=\frac{(1-\gamma)\left(1+i_{B}\right)}{\sqrt{X_{G R}}} \delta_{A}^{G R}>0 \\
\frac{d \delta_{A}^{A C}}{d \delta_{B}}= & \frac{\left(1+i_{B}\right)(9 \mu-5)\left(1-\sqrt{X_{A C}}\right)}{\left(1+i_{A}\right)\left(9 \mu^{2}-5\right)}+\frac{\left(1+i_{B}\right)(9 \mu-5)}{\left(1+i_{A}\right)\left(9 \mu^{2}-5\right) \sqrt{X_{A C}}} \frac{\left(9 \mu^{2}-5\right)\left[\left(5 t^{2} \gamma^{2}+36 t \gamma \Delta-16 \Delta^{2}\right)+\frac{180 t \gamma}{m}\left(F_{G R}-F_{A C}\right)\right]}{(3 t \gamma(5-2 \mu)-2 \Delta(9 \mu-5))^{2}}+ \\
& \frac{8\left(1+i_{B}\right)\left(\frac{9}{8} t \gamma-\Delta\right)}{45\left(1+i_{A}\right) \lambda \sqrt{X_{A C}}} .
\end{aligned}
$$

With $\frac{\left(9 \mu^{2}-5\right)\left[\left(5 t^{2} \gamma^{2}+36 t \gamma \Delta-16 \Delta^{2}\right)+\frac{180 t \gamma}{m}\left(F_{G R}-F_{A C}\right)\right]}{(3 t \gamma(5-2 \mu)-2 \Delta(9 \mu-5))^{2}}=X_{A C}-1=\left(\sqrt{X_{A C}}-1\right)\left(\sqrt{X_{A C}}+1\right)$ we get

$$
\begin{aligned}
\frac{d \delta_{A}^{A C}}{d \delta_{B}}= & \frac{2\left(1+i_{B}\right)(1-\gamma)(9 \mu-5)}{45 \lambda} \frac{3 t \gamma(5-2 \mu)-2 \Delta(9 \mu-5)}{2\left(9 \mu^{2}-5\right)(1-\gamma)\left(1+i_{A}\right)}\left(1-\sqrt{X_{A C}}\right)- \\
& \frac{2\left(1+i_{B}\right)(1-\gamma)(9 \mu-5)\left(1+\sqrt{X_{A C}}\right)}{45 \lambda \sqrt{X_{A C}}} \frac{3 t \gamma(5-2 \mu)-2 \Delta(9 \mu-5)}{2\left(9 \mu^{2}-5\right)(1-\gamma)\left(1+i_{A}\right)}\left(1-\sqrt{X_{A C}}\right)+\frac{8\left(1+i_{B}\right)\left(\frac{9}{8} t \gamma-\Delta\right)}{45\left(1+i_{A}\right) \lambda \sqrt{X_{A C}}}
\end{aligned}
$$

Since $\frac{3 t \gamma(5-2 \mu)-2 \Delta(9 \mu-5)}{2\left(9 \mu^{2}-5\right)(1-\gamma)\left(1+i_{A}\right)}\left(1-\sqrt{X_{A C}}\right)=\delta_{A}^{A C}$ it follows that

$$
\frac{d \delta_{A}^{A C}}{d \delta_{B}}=\frac{2\left(1+i_{B}\right)\left[4\left(\frac{9}{8} t \gamma-\Delta\right)-(1-\gamma)\left(1+i_{A}\right)(9 \mu-5) \delta_{A}^{A C}\right]}{45 \lambda\left(1+i_{A}\right) \sqrt{X_{A C}}} .
$$

Note that $4\left(\frac{9}{8} t \gamma-\Delta\right)-(1-\gamma)\left(1+i_{A}\right)(9 \mu-5) \delta_{A}^{A C}>0$ is equivalent to $\frac{9}{8} t \gamma-\Delta-\frac{9 \mu-5}{4}(1-$ $\gamma)\left(1+i_{A}\right) \delta_{A}^{A C}>0$ which holds due to Condition (2) as $\frac{9 \mu-5}{4}<\mu$. Hence, $\frac{d \delta_{A}^{A C}}{d \delta_{B}}>0$ holds.

\section{Proof of Proposition 7:}

$\frac{d \delta_{A}^{C B L}}{d i_{B}}=-\frac{1-(1-\gamma) \delta_{B}}{\alpha \mu(1-\gamma)\left(1+i_{A}\right)}<0$ and $\frac{d \delta_{A}^{G R}}{d i_{B}}=-\frac{1-(1-\gamma) \delta_{B}}{\sqrt{X_{G R}}} \delta_{A}^{G R}<0$. Note that $\left|\frac{d \delta_{A}^{C B L}}{d i_{B}}\right|>\left|\frac{d \delta_{A}^{G R}}{d i_{B}}\right|$ is equivalent to $\frac{1}{\alpha}>-\frac{\frac{5}{6} t \gamma+\Delta}{\sqrt{X_{G R}}}$ which is fulfilled as $\frac{5}{6} t \gamma+\Delta>0$ due to Condition (1).

$$
\begin{aligned}
\frac{d \delta_{A}^{A C}}{d i_{B}}= & \frac{2\left(\frac{1}{9}-\frac{1}{5} \mu\right)\left[1-(1-\gamma) \delta_{B}\right]}{\lambda} \frac{3 t \gamma(5-2 \mu)-2 \Delta(9 \mu-5)}{2\left(9 \mu^{2}-5\right)(1-\gamma)\left(1+i_{A}\right)}\left(1-\sqrt{X_{A C}}\right)-\frac{8\left[1-(1-\gamma) \delta_{B}\right]\left(\frac{9}{8} t \gamma-\Delta\right)}{45(1-\gamma)\left(1+i_{A}\right) \lambda \sqrt{X_{A C}}}+ \\
& \frac{\left[1-(1-\gamma) \delta_{B}\right]\left(\frac{1}{9}-\frac{1}{5} \mu\right)}{(1-\gamma)\left(1+i_{A}\right) \sqrt{X_{A C}}\left(\frac{\mu^{2}}{5}-\frac{1}{9}\right)} \frac{\left(9 \mu^{2}-5\right)\left[\left(5 t^{2} \gamma^{2}+36 t \gamma \Delta-16 \Delta^{2}\right)+\frac{180 t \gamma}{m}\left(F_{G R}-F_{A C}\right)\right]}{(3 t \gamma(5-2 \mu)-2 \Delta(9 \mu-5))^{2}}
\end{aligned}
$$

With $\frac{\left(9 \mu^{2}-5\right)\left[\left(5 t^{2} \gamma^{2}+36 t \gamma \Delta-16 \Delta^{2}\right)+\frac{180 t \gamma}{m}\left(F_{G R}-F_{A C}\right)\right]}{(3 t \gamma(5-2 \mu)-2 \Delta(9 \mu-5))^{2}}=X_{A C}-1=\left(\sqrt{X_{A C}}-1\right)\left(\sqrt{X_{A C}}+1\right)$ we get

$$
\begin{aligned}
\frac{d \delta_{A}^{A C}}{d i_{B}}= & \frac{2\left(\frac{1}{9}-\frac{1}{5} \mu\right)\left[1-(1-\gamma) \delta_{B}\right]}{\lambda} \frac{3 t \gamma(5-2 \mu)-2 \Delta(9 \mu-5)}{2\left(9 \mu^{2}-5\right)(1-\gamma)\left(1+i_{A}\right)}\left(1-\sqrt{X_{A C}}\right)-\frac{8\left[1-(1-\gamma) \delta_{B}\right]\left(\frac{9}{8} t \gamma-\Delta\right)}{45(1-\gamma)\left(1+i_{A}\right) \lambda \sqrt{X_{A C}}} \\
& -\frac{2\left[1-(1-\gamma) \delta_{B}\right]\left(\frac{1}{9}-\frac{1}{5} \mu\right)\left(1+\sqrt{X_{A C}}\right)}{\lambda \sqrt{X_{A C}}} \frac{3 t \gamma(5-2 \mu)-2 \Delta(9 \mu-5)}{2\left(9 \mu^{2}-5\right)(1-\gamma)\left(1+i_{A}\right)}\left(1-\sqrt{X_{A C}}\right) .
\end{aligned}
$$

Since $\frac{3 t \gamma(5-2 \mu)-2 \Delta(9 \mu-5)}{2\left(9 \mu^{2}-5\right)(1-\gamma)\left(1+i_{A}\right)}\left(1-\sqrt{X_{A C}}\right)=\delta_{A}^{A C}$ it follows that

$$
\frac{d \delta_{A}^{A C}}{d i_{B}}=-\frac{2\left[1-(1-\gamma) \delta_{B}\right]\left[4\left(\frac{9}{8} t \gamma-\Delta\right)-(1-\gamma)\left(1+i_{A}\right)(9 \mu-5) \delta_{A}^{A C}\right]}{45 \lambda \sqrt{X_{A C}}(1-\gamma)\left(1+i_{A}\right)} .
$$

\footnotetext{
${ }^{12}$ In order to keep our analysis tractable, we henceforth assume $\mu>0.6$. We think this is justified since in that case, the foreign bank would not lose more than 40 percent of its screening efficiency due to soft information problems which seems reasonable.
} 
Note that $4\left(\frac{9}{8} t \gamma-\Delta\right)-(1-\gamma)\left(1+i_{A}\right)(9 \mu-5) \delta_{A}^{A C}>0$ is equivalent to $\frac{9}{8} t \gamma-\Delta-\frac{9 \mu-5}{4}(1-$ $\gamma)\left(1+i_{A}\right) \delta_{A}^{A C}>0$ which holds due to Condition (2) as $\frac{9 \mu-5}{4}<\mu$. Hence, $\frac{d \delta_{A}^{A C}}{d i_{B}}<0$ holds.

\section{Proof of Proposition 8:}

$\frac{d \delta_{A}^{C B L}}{d \frac{1}{t}}=\frac{5 \gamma t^{2}}{4 \alpha \mu(1-\gamma)\left(1+i_{A}\right)}\left(\frac{2}{3}-\sqrt{\frac{F_{C B L}}{m t \gamma}}\right)$

Note, first, that $\delta_{A}^{C B L}<1$ is equivalent to $\sqrt{\frac{F_{C B L}}{m t \gamma}}<\frac{1}{3}+\frac{2 \alpha \mu(1-\gamma)\left(1+i_{A}\right)+2 \Delta}{5 t \gamma}$. Second, as we abstract from exit of domestic banks it must hold that $\widetilde{\phi}_{B}^{C B L} \geq \frac{1}{6}$ which is equivalent to $\frac{5}{6} t \gamma-\Delta-\alpha \mu(1-\gamma)\left(1+i_{A}\right) \delta_{A} \geq 0$. Accordingly, $\frac{2 \alpha \mu(1-\gamma)\left(1+i_{A}\right)+2 \Delta}{5 t \gamma} \leq \frac{1}{3}$ which is equivalent to $\frac{5}{6} t \gamma-\Delta-\alpha \mu(1-\gamma)\left(1+i_{A}\right) \geq 0$ is fulfilled. Consequently, it must hold that $\sqrt{\frac{F_{C B L}}{m t \gamma}}<\frac{2}{3}$. Hence, it holds that $\frac{d \delta_{A}^{C B L}}{d \frac{1}{t}}>0$.

$\frac{d \delta_{A}^{G R}}{d \frac{1}{t}}=\frac{5 t^{2} \gamma}{6 \sqrt{X_{G R}}}\left[\delta_{A}^{G R}-\frac{15\left(F_{G R}-F_{C B L}\right)}{4 m \mu(1-\alpha)(1-\gamma)\left(1+i_{A}\right)}\right]$

Note that $\frac{d \delta_{A}^{G R}}{d \frac{1}{t}}>0$ is equivalent to $\delta_{A}^{G R}>\frac{15\left(F_{G R}-F_{C B L}\right)}{4 m \mu(1-\alpha)(1-\gamma)\left(1+i_{A}\right)}$. Thus, it holds that $\frac{d \delta_{A}^{G R}}{d \frac{1}{t}}>0$ for $\delta_{A}^{G R}>\frac{15\left(F_{G R}-F_{C B L}\right)}{4 m \mu(1-\alpha)(1-\gamma)\left(1+i_{A}\right)}$ and $\frac{d \delta_{A}^{G R}}{d \frac{1}{t}}<0$ for $\delta_{A}^{G R}<\frac{15\left(F_{G R}-F_{C B L}\right)}{4 m \mu(1-\alpha)(1-\gamma)\left(1+i_{A}\right)}$.

$$
\begin{aligned}
\frac{d \delta_{A}^{A C}}{d \frac{1}{t}}= & -\frac{\gamma t^{2}\left(1-\frac{2}{5} \mu\right)}{3 \lambda} \frac{3 t \gamma(5-2 \mu)-2 \Delta(9 \mu-5)}{2\left(9 \mu^{2}-5\right)(1-\gamma)\left(1+i_{A}\right)}\left(1-\sqrt{X_{A C}}\right)-\frac{t^{2} \gamma\left[-\frac{101}{360} t \gamma+\frac{1}{5}\left(\frac{9}{8} t \gamma-\Delta\right)-\frac{\left(F_{G R}-F_{A C}\right)}{m}\right]}{(1-\gamma)\left(1+i_{A}\right) \lambda \sqrt{X_{A C}}}- \\
& \frac{\gamma t^{2}\left(1-\frac{2}{5} \mu\right)}{6(1-\gamma)\left(1+i_{A}\right) \sqrt{X_{A C}}\left(\frac{\mu^{2}}{5}-\frac{1}{9}\right)} \frac{\left(9 \mu^{2}-5\right)\left[\left(5 t^{2} \gamma^{2}+36 t \gamma \Delta-16 \Delta^{2}\right)+\frac{180 t \gamma}{m}\left(F_{G R}-F_{A C}\right)\right]}{(3 t \gamma(5-2 \mu)-2 \Delta(9 \mu-5))^{2}} .
\end{aligned}
$$

With $\frac{\left(9 \mu^{2}-5\right)\left[\left(5 t^{2} \gamma^{2}+36 t \gamma \Delta-16 \Delta^{2}\right)+\frac{180 t \gamma}{m}\left(F_{G R}-F_{A C}\right)\right]}{(3 t \gamma(5-2 \mu)-2 \Delta(9 \mu-5))^{2}}=X_{A C}-1=\left(\sqrt{X_{A C}}-1\right)\left(\sqrt{X_{A C}}+1\right)$ we get

$$
\begin{aligned}
\frac{d \delta_{A}^{A C}}{d \frac{1}{t}}= & -\frac{\gamma t^{2}\left(1-\frac{2}{5} \mu\right)}{3 \lambda} \frac{3 t \gamma(5-2 \mu)-2 \Delta(9 \mu-5)}{2\left(9 \mu^{2}-5\right)(1-\gamma)\left(1+i_{A}\right)}\left(1-\sqrt{X_{A C}}\right)-\frac{t^{2} \gamma\left[-\frac{101}{360} t \gamma+\frac{1}{5}\left(\frac{9}{8} t \gamma-\Delta\right)-\frac{\left(F_{\left.G R^{-}-F_{A C}\right)}\right.}{m}\right]}{(1-\gamma)\left(1+i_{A}\right) \lambda \sqrt{X_{A C}}}+ \\
& \frac{\gamma t^{2}\left(1-\frac{2}{5} \mu\right)}{3 \lambda} \frac{\left(1+\sqrt{X_{A C}}\right)}{\sqrt{X_{A C}}} \frac{3 t \gamma(5-2 \mu)-2 \Delta(9 \mu-5)}{2\left(9 \mu^{2}-5\right)(1-\gamma)\left(1+i_{A}\right)}\left(1-\sqrt{X_{A C}}\right) .
\end{aligned}
$$

Using $\frac{3 t \gamma(5-2 \mu)-2 \Delta(9 \mu-5)}{2\left(9 \mu^{2}-5\right)(1-\gamma)\left(1+i_{A}\right)}\left(1-\sqrt{X_{A C}}\right)=\delta_{A}^{A C}$ we arrive at

$\frac{d \delta_{A}^{A C}}{d \frac{1}{t}}=\frac{\gamma t^{2}\left[(1-\gamma)\left(1+i_{A}\right)(5-2 \mu) \delta_{A}^{A C}+\frac{5}{6} t \gamma+3 \Delta+\frac{15}{m}\left(F_{G R}-F_{A C}\right)\right]}{15(1-\gamma)\left(1+i_{A}\right) \lambda \sqrt{X_{A C}}}$.

We now prove that $\frac{d \delta_{A}^{A C}}{d \frac{1}{t}}>0 . \frac{d \delta_{A}^{A C}}{d \frac{1}{t}}>0$ is equivalent to $F_{A C}-F_{G R}<\frac{m}{15}\left[\frac{5}{6} t \gamma+\Delta+2 \Delta+\right.$ $\left.(5-2 \mu)(1-\gamma)\left(1+i_{A}\right) \delta_{A}^{A C}\right]$. Note, beforehand, that in case of acquisition entry $\widetilde{\phi}_{B}^{A C} \leq \frac{1}{2}$ must hold due to $i_{B}-i_{A}>0, \delta_{A}>\delta_{B}$ and $\mu=0 . \widetilde{\phi}_{B}^{A C} \leq \frac{1}{2}$ is equivalent to $2 \Delta+2(1-\gamma)\left(1+i_{A}\right) \delta_{A} \geq$ 0 . As the minimum of $(5-2 \mu)$ is $3,2 \Delta+(5-2 \mu)(1-\gamma)\left(1+i_{A}\right) \delta_{A}^{A C}>0$ must then also hold. As $\frac{5}{6} t \gamma+\Delta>0$ due to Condition (3), it follows that the right hand side of the above inequality is positive. However, the left hand side of that expression is negative. As a consequence, the above inequality is fulfilled and it holds that $\frac{d \delta_{A}^{A C}}{d \frac{1}{t}}>0$. 


\section{Proof of Proposition 9:}

$\frac{d \delta_{A}^{C B L}}{d m}=\frac{-5 t \gamma}{4 \alpha m \mu(1-\gamma)\left(1+i_{A}\right)} \sqrt{\frac{F_{C B L}}{m t \gamma}}<0 ; \frac{d \delta_{A}^{G R}}{d m}=\frac{-25 t \gamma\left(F_{G R}-F_{C B L}\right)}{8 \mu m^{2}(1-\alpha)(1-\gamma)\left(1+i_{A}\right) \sqrt{X_{G R}}}<0 ; \frac{d \delta_{A}^{A C}}{d m}=\frac{t \gamma\left(F_{G R}-F_{A C}\right)}{\lambda m^{2}(1-\gamma)\left(1+i_{A}\right) \sqrt{X_{A C}}}>$ 0 .

\section{Proof of Lemma 4:}

\section{(1) No Entry:}

Consumer surplus is given by $v m \gamma+0 \cdot m(1-\gamma)-\widetilde{r}_{N E}^{B} m \gamma-4 m \int_{0}^{\frac{1}{4}} x t d x$. Producer surplus is given by $2 \pi_{B}^{N E}=m t \gamma \cdot\left(\frac{1}{2}\right)^{2}$. Rearranging yields $W_{N E}=m\left[\gamma\left(v-i_{B}\right)-(1-\gamma)\left(1-\delta_{B}\right)\left(1+i_{B}\right)-\frac{t}{8}\right]{ }^{13}$

(2) Cross Border Lending:

Consumer surplus is given by $v m \gamma+0 \cdot m(1-\gamma)-\left(\widetilde{r}_{A}^{C B L} \widetilde{\phi}_{A}^{C B L}+2 \widetilde{r}_{B}^{C B L} \widetilde{\phi}_{B}^{C B L}\right) m \gamma-2 m\left(\int_{0}^{\frac{1}{6}} x t d x+\right.$ $\left.\int_{0}^{x_{A, B}^{C B L}} x t d x+\int_{0}^{x_{A, B}^{C B L}} x t d x\right)$. Producer surplus is given by $2 \pi_{B}^{C B L}$. Rearranging yields

$$
\begin{aligned}
W_{C B L}= & m\left\{\gamma v-\frac{t}{12}-\frac{1}{3} \gamma\left(\widetilde{r}_{A}^{C B L}+2 \widetilde{r}_{B}^{C B L}\right)+\frac{1}{t}\left(\gamma-\frac{1}{2}\right)\left(\widetilde{r}_{B}^{C B L}-\widetilde{r}_{A}^{C B L}\right)^{2}+\right. \\
& \left.2\left[\frac{1}{3}-\frac{1}{2 t}\left(\widetilde{r}_{B}^{C B L}-\widetilde{r}_{A}^{C B L}\right)\right]\left[\gamma\left(\widetilde{r}_{B}^{C B L}-i_{B}\right)-(1-\gamma)\left(1-\delta_{B}\right)\left(1+i_{B}\right)\right]\right\} .
\end{aligned}
$$

\section{(3) Greenfield Entry}

Consumer surplus is given by $v m \gamma+0 \cdot m(1-\gamma)-\left(\widetilde{r}_{A}^{G R} \widetilde{\phi}_{A}^{G R}+2 \widetilde{r}_{B}^{G R} \widetilde{\phi}_{B}^{G R}\right) m \gamma-2 m\left(\int_{0}^{\frac{1}{6}} x t d x+\right.$ $\left.\int_{0}^{x_{A, B_{1}}^{G R}} x t d x+\int_{0}^{\frac{1}{3}-x_{A, B_{1}}^{G R}} x t d x\right)$. Producer surplus is given by $2 \pi_{B}^{G R}$. Rearranging yields

$$
\begin{gathered}
W_{G R}=m\left\{\gamma v-\frac{t}{12}-\frac{1}{3} \gamma\left(\widetilde{r}_{A}^{G R}+2 \widetilde{r}_{B}^{G R}\right)+\frac{1}{t}\left(\gamma-\frac{1}{2}\right)\left(\widetilde{r}_{B}^{G R}-\widetilde{r}_{A}^{G R}\right)^{2}+2\left[\frac{1}{3}-\frac{1}{2 t}\left(\widetilde{r}_{B}^{G R}-\widetilde{r}_{A}^{G R}\right)\right]\right. \\
\left.\left[\gamma\left(\widetilde{r}_{B}^{G R}-i_{B}\right)-(1-\gamma)\left(1-\delta_{B}\right)\left(1+i_{B}\right)\right]\right\} .
\end{gathered}
$$

\section{(4) Entry via Acquisition}

Consumer surplus is given by $v m \gamma+0 \cdot m(1-\gamma)-\left(\widetilde{r}_{A}^{A C} \widetilde{\phi}_{A}^{A C}+\widetilde{r}_{B}^{A C} \widetilde{\phi}_{B}^{A C}\right) m \gamma-2 m\left(\int_{0}^{x_{A, B}^{A C}} x t d x+\right.$ $\frac{1}{2}-x_{A, B}^{A C}$

$\left.\int_{0}^{A, B} x t d x\right)$. Producer surplus is given by $\pi_{B}^{A C}$ and the acquisition price amounts to $\pi_{B}^{G R}$. Rearranging yields

$W_{A C}=m\left\{\gamma\left[v-\widetilde{r}_{A}^{A C}\left(\frac{1}{2}+\frac{1}{t}\left(\widetilde{r}_{B}^{A C}-\widetilde{r}_{A}^{A C}\right)\right)-\left(\frac{1}{2}-\frac{1}{t}\left(\widetilde{r}_{B}^{A C}-\widetilde{r}_{A}^{A C}\right)\right) i_{B}\right]-\right.$

\footnotetext{
${ }^{13}$ For our analysis to be interesting, we assume $W_{N E}>0$.
} 


$$
\begin{aligned}
& \left(\frac{1}{2}-\frac{1}{t}\left(\widetilde{r}_{B}^{A C}-\widetilde{r}_{A}^{A C}\right)\right)(1-\gamma)\left(1-\delta_{B}\right)\left(1+i_{B}\right)-\frac{t}{2}\left[\frac{1}{4}+\frac{1}{t^{2}}\left(\widetilde{r}_{B}^{A C}-\widetilde{r}_{A}^{A C}\right)^{2}\right]+ \\
& \left.\frac{1}{25 t \gamma}\left[\frac{5}{3} t \gamma-\Delta-\mu(1-\gamma)\left(1+i_{A}\right) \delta_{A}\right]^{2}\right\} .
\end{aligned}
$$

\section{Proof of Proposition 10:}

\section{Shape of Welfare Functions:}

$$
\begin{aligned}
& \frac{d W_{N E}}{d \delta_{A}}=0 \\
& \left.\frac{d W_{C B L}}{d \delta_{A}}\right|_{\delta_{A}=0}=\frac{\alpha m \mu(1-\gamma)\left(1+i_{A}\right)}{75 t \gamma^{2}}\left[5 t \gamma^{2}+12(3 \gamma-1)\left(i_{B}-i_{A}\right)\right]>0 \\
& \frac{d^{2} W_{C B L}}{d \delta_{A}^{2}}=\frac{m(1-\gamma)\left(4 \gamma-1-3 \gamma^{2}\right)}{t}\left(\frac{2 \alpha \mu\left(1+i_{A}\right)}{5 \gamma}\right)^{2}>0 \\
& \left.\frac{d W_{G R}}{d \delta_{A}}\right|_{\delta_{A}=0}=\frac{m \mu(1-\gamma)\left(1+i_{A}\right)}{75 t \gamma^{2}}\left[5 t \gamma^{2}+12(3 \gamma-1)\left(i_{B}-i_{A}\right)\right]>0 \\
& \frac{d^{2} W_{G R}}{d \delta_{A}^{2}}=\frac{m(1-\gamma)\left(4 \gamma-1-3 \gamma^{2}\right)}{t}\left(\frac{2 \mu\left(1+i_{A}\right)}{5 \gamma}\right)^{2}>0 \\
& \left.\frac{d W_{A C}}{d \delta_{A}}\right|_{\delta_{A}=0}=\frac{m\left(1+i_{A}\right)(1-\gamma)}{450 t \gamma^{2}}\left[15 t \gamma^{2}(5-4 \mu)+2(100 \gamma+18 \mu \gamma-25)\left(i_{B}-i_{A}\right)\right]>0 \\
& \frac{d^{2} W_{A C}}{d \delta_{A}^{2}}=\frac{m\left(18 \gamma \mu^{2}+100 \gamma-25\right)}{t}\left(\frac{(1-\gamma)\left(1+i_{A}\right)}{15 \gamma}\right)^{2}>0
\end{aligned}
$$

Note that $4 \gamma-1-3 \gamma^{2}>0$ as well as $18 \gamma \mu^{2}+100 \gamma-25>0$ hold for $\gamma>0.5$ which we will assume henceforth. We find, first, that $W_{N E}$ is independent of $\delta_{A}$. Second, $W_{C B L}, W_{G R}$, and $W_{A C}$ are quadratic, increasing, and convex functions in $\delta_{A}$ with $\underset{\delta_{A} \in \mathbb{R}}{\arg \min }\left(W_{C B L}\right)<0$, $\underset{\delta_{A} \in \mathbb{R}}{\arg \min }\left(W_{G R}\right)<0$, and $\underset{\delta_{A} \in \mathbb{R}}{\arg \min }\left(W_{A C}\right)<0$ since the second order conditions with respect to $\delta_{A}$ are positive and since the first order conditions with respect to $\delta_{A}$ at $\delta_{A}=0$ are positive as well. Next, we show that $W_{G R}>W_{C B L}$ always holds. $W_{G R}-W_{C B L}>0$ is equivalent to $\frac{2}{25 t \gamma} m \mu \delta_{A}(1-\gamma)\left(1+i_{A}\right)(1-\alpha)\left\{\frac{5}{6} t \gamma+2 \frac{(3 \gamma-1)}{\gamma}\left[\Delta+\frac{1}{2} \mu \delta_{A}(1-\gamma)\left(1+i_{A}\right)(1+\alpha)\right]\right\}>0$ which is fulfilled if we assume $\Delta>0 .{ }^{14}$ Hence, we only need to calculate the intersection points of $W_{N E}, W_{G R}$, and $W_{A C}$.

\section{(a) Intersection between $W_{N E}$ and $W_{G R}$}

Note that $W_{G R}-W_{N E}>0$ is equivalent to

$\frac{1}{1800} \frac{m}{t \gamma^{2}}\left\{144 \mu^{2}(3 \gamma-1)(1-\gamma)^{2}\left(1+i_{A}\right)^{2}\left(\delta_{A}\right)^{2}+24 \mu(1-\gamma)\left(1+i_{A}\right)\left[5 t \gamma^{2}+12(3 \gamma-1) \Delta\right] \delta_{A}\right.$ $\left.-5 t \gamma^{2}[5 t(8 \gamma-3)-24 \Delta]+144(3 \gamma-1) \Delta^{2}\right\}>0$.

Solving for $\delta_{A}$ yields $\delta_{A}<\frac{\frac{5}{12} t \gamma\left(-\sqrt{25 \gamma^{2}-17 \gamma+3}-\gamma\right)-(3 \gamma-1) \Delta}{\mu(1-\gamma)(3 \gamma-1)\left(1+i_{A}\right)}$ and $\delta_{A}>\frac{\frac{5}{12} t \gamma\left(+\sqrt{25 \gamma^{2}-17 \gamma+3}-\gamma\right)-(3 \gamma-1) \Delta}{\mu(1-\gamma)(3 \gamma-1)\left(1+i_{A}\right)}$.

\footnotetext{
${ }^{14}$ Regarding the welfare analysis, we only look at host banking markets on a rather low financial development stage and assume henceforth $\Delta=i_{B}-i_{A}-(1-\gamma)\left(1+i_{B}\right) \delta_{B}>0$. This expression is the more likely fulfilled the larger is the difference in refinancing conditions of foreign and host country banks and the lower is the screening ability of host country banks. This limitation seems justified as the entry of foreign banks into financially very well developed countries is, in general, not very much regulated.
} 
Since, as derived above, $\underset{\delta_{A} \in \mathbb{R}}{\arg \min }\left(W_{G R}\right)<0, \frac{d W_{N E}}{d \delta_{A}}=0$ and $\left.\frac{d W_{G R}}{d \delta_{A}}\right|_{\delta_{A}=0}>0$, only one intersection between $W_{N E}$ and $W_{G R}$ for $0<\delta_{A}<1$ is possible so that we only need to consider the intersection point $\delta_{A}=\frac{\frac{5}{12} t \gamma\left(\sqrt{25 \gamma^{2}-17 \gamma+3}-\gamma\right)-(3 \gamma-1) \Delta}{\mu(1-\gamma)(3 \gamma-1)\left(1+i_{A}\right)}$.

Hence, $W_{G R}>W_{N E}$ is equivalent to $\delta_{A}>\frac{\frac{5}{12} t \gamma\left(\sqrt{25 \gamma^{2}-17 \gamma+3}-\gamma\right)-(3 \gamma-1) \Delta}{\mu(1-\gamma)(3 \gamma-1)\left(1+i_{A}\right)} \equiv \delta_{W}^{G R}$.

(b) Intersection between $W_{G R}$ and $W_{A C}$

Note that $W_{A C}-W_{G R}>0$ is equivalent to

$$
\begin{aligned}
& \frac{1}{1800} \frac{m}{t \gamma^{2}}\left\{4(1-\gamma)^{2}\left(1+i_{A}\right)^{2}\left(100 \gamma-25+36 \mu^{2}-90 \mu^{2} \gamma\right)\left(\delta_{A}\right)^{2}-4(1-\gamma)\left(1+i_{A}\right)\left[\left(15 t \gamma^{2}(6 \mu-5)\right.\right.\right. \\
& \left.-2(100 \gamma-25+36 \mu-90 \gamma \mu) \Delta)] \delta_{A}+4(10 \gamma+11) \Delta^{2}-25 t^{2} \gamma^{2}(2 \gamma+3)-60 t \gamma^{2} \Delta\right\}>0
\end{aligned}
$$

Solving for $\delta_{A}$ yields $\delta_{A}<x_{A C}^{W}-\frac{5 \sqrt{X_{A C}^{W}}}{2(1-\gamma)\left(1+i_{A}\right)\left[25(4 \gamma-1)-18 \mu^{2}(5 \gamma-2)\right]}$ and

$\delta_{A}>x_{A C}^{W}+\frac{5 \sqrt{X_{A C}^{W}}}{2(1-\gamma)\left(1+i_{A}\right)\left[25(4 \gamma-1)-18 \mu^{2}(5 \gamma-2)\right]}$

with $x_{A C}^{W} \equiv \frac{\left[\frac{15}{2} t \gamma(6 \mu-5) \gamma-[25(4 \gamma-1)-18 \mu(5 \gamma-2)] \Delta\right]}{(1-\gamma)\left(1+i_{A}\right)\left[25(4 \gamma-1)-18 \mu^{2}(5 \gamma-2)\right]}$ and

$$
\begin{aligned}
& X_{A C}^{W} \equiv t \gamma^{2}\left\{t\left[25\left(10 \gamma+17 \gamma^{2}-3\right)+18 \mu\left(6 \mu-30 \gamma^{2}-11 \gamma \mu+8 \gamma^{2} \mu\right)\right]+\right. \\
&72(1-\mu)[5 \gamma(4-3 \mu)+6 \mu-5] \Delta\}+72(1-\mu)^{2}(4 \gamma-1)(5 \gamma-2) \Delta^{2} .
\end{aligned}
$$

In principle, two intersections of $W_{A C}$ and $W_{G R}$ for $\delta_{A}>0$ are possible. However, remember that $\left.\frac{d W_{G R}}{d \delta_{A}}\right|_{\delta_{A}=0}>0$ as well as $\left.\frac{d W_{A C}}{d \delta_{A}}\right|_{\delta_{A}=0}>0$. Hence, by proofing that $\left.W_{G R}\right|_{\delta_{A}=0}>\left.W_{A C}\right|_{\delta_{A}=0}$ we show that we only need to consider the upper intersection point $x_{A C}^{W}+\frac{5 \sqrt{X_{A C}^{W}}}{2(1-\gamma)\left(1+i_{A}\right)\left[25(4 \gamma-1)-18 \mu^{2}(5 \gamma-2)\right]}$. Note that $\left.W_{G R}\right|_{\delta_{A}=0}-\left.W_{A C}\right|_{\delta_{A}=0}=m \frac{25 t^{2} \gamma^{2}(2 \gamma+3)-4 \Delta^{2}(10 \gamma+11)+60 t \gamma^{2} \Delta}{1800 t \gamma^{2}}$. Further, $25 t^{2} \gamma^{2}(2 \gamma+3)-$ $4 \Delta^{2}(10 \gamma+11)>0$ is equivalent to $\frac{5}{6} t \gamma-\frac{1}{3} \sqrt{\frac{(10 \gamma+11)}{(2 \gamma+3)}} \Delta>0$. Numerical solutions show that $0<\frac{1}{3} \sqrt{\frac{(10 \gamma+11)}{(2 \gamma+3)}}<1$ so that Condition (2) is fulfilled and, hence, it must hold that $\left.W_{G R}\right|_{\delta_{A}=0}>\left.W_{A C}\right|_{\delta_{A}=0}$. It follows that $W_{A C}>W_{G R}$ holds for

$\delta_{A}>x_{A C}^{W}+\frac{5 \sqrt{X_{A C}^{W}}}{2(1-\gamma)\left(1+i_{A}\right)\left[25(4 \gamma-1)-18 \mu^{2}(5 \gamma-2)\right]} \equiv \delta_{W}^{A C}$.

As we can abstract from the lower threshold, it must further hold that $\left.\frac{d W_{A C}}{d \delta_{A}}\right|_{\delta_{A}=\delta_{W}^{A C}}>\left.\frac{d W_{G R}}{d \delta_{A}}\right|_{\delta_{A}=\delta_{W}^{A C}}$.

(c) Intersection of $W_{N E}$ and $W_{A C}$ and proof of $\delta_{W}^{G R}<\delta_{W}^{A C}$

Note, first, that it is useful to show that $\delta_{W}^{G R}<\delta_{W}^{A C} . \delta_{W}^{G R}<\delta_{W}^{A C}$ is equivalent to

$$
\begin{aligned}
& \frac{5}{2\left[25(4 \gamma-1)-18 \mu^{2}(5 \gamma-2)\right]}\left(t \gamma ^ { 2 } \left\{t\left[25\left(10 \gamma+17 \gamma^{2}-3\right)+18 \mu\left(6 \mu-30 \gamma^{2}-11 \gamma \mu+8 \gamma^{2} \mu\right)\right]+\right.\right. \\
& \left.72(1-\mu)[5 \gamma(4-3 \mu)+6 \mu-5] \Delta\}+72(1-\mu)^{2}(4 \gamma-1)(5 \gamma-2) \Delta^{2}\right)^{\frac{1}{2}}> \\
& \frac{1}{2 \mu(3 \gamma-1)\left[25(4 \gamma-1)-18 \mu^{2}(5 \gamma-2)\right]}\left\{-\gamma\left(90 \mu+100 \gamma+234 \mu^{2} \gamma-270 \mu \gamma-72 \mu^{2}-25\right)+\right. \\
& \left.\left.\left[25(4 \gamma-1)-18 \mu^{2}(5 \gamma-2)\right] \sqrt{-17 \gamma+25 \gamma^{2}+3}\right]\right\} \\
& {\left[\frac{5}{6} t \gamma+\frac{-50(4 \gamma-1)(3 \gamma-1)(1-\mu)}{\left[25(4 \gamma-1)-18 \mu^{2}(5 \gamma-2)\right] \sqrt{-17 \gamma+25 \gamma^{2}+3}-\gamma\left(90 \mu+100 \gamma+234 \mu^{2} \gamma-270 \mu \gamma-72 \mu^{2}-25\right)} \Delta\right] .}
\end{aligned}
$$


Numerical simulations show that $25(4 \gamma-1)-18 \mu^{2}(5 \gamma-2)>0$ so that the left hand side of this expression is clearly positive. The right hand side is also positive as numerical simulations show that $\left\{-\gamma\left(90 \mu+100 \gamma+234 \mu^{2} \gamma-270 \mu \gamma-72 \mu^{2}-25\right)+\left[25(4 \gamma-1)-18 \mu^{2}(5 \gamma-2)\right] \sqrt{-17 \gamma+25 \gamma^{2}+3}\right\}$ is positive and $-1<\frac{-50(4 \gamma-1)(3 \gamma-1)(1-\mu)}{\sqrt{-17 \gamma+25 \gamma^{2}+3}\left(100 \gamma-90 \mu^{2} \gamma+36 \mu^{2}-25\right)-\gamma\left(90 \mu+100 \gamma+234 \mu^{2} \gamma-270 \mu \gamma-72 \mu^{2}-25\right)}<1$ such that $\left[\frac{5}{6} t \gamma+\frac{-50(4 \gamma-1)(3 \gamma-1)(1-\mu)}{\sqrt{-17 \gamma+25 \gamma^{2}+3}\left(100 \gamma-90 \mu^{2} \gamma+36 \mu^{2}-25\right)-\gamma\left(90 \mu+100 \gamma+234 \mu^{2} \gamma-270 \mu \gamma-72 \mu^{2}-25\right)} \Delta\right]>0$ holds according to Condition (1). Squaring and rearranging yields

$$
\begin{aligned}
& {\left[25(4 \gamma-1)-18 \mu^{2}(5 \gamma-2)\right]\left\{\frac{144}{5}(3 \gamma-1)(1-\mu) \Delta[\gamma(18 \mu(3 \gamma-1)-5(4 \gamma-1))+\right.} \\
& \left.5 \sqrt{-17 \gamma+25 \gamma^{2}+3}(4 \gamma-1)\right]\left[\frac{5}{6} t \gamma-\frac{5(4 \gamma-1)(3 \gamma-1)(1-\mu)}{\gamma[18 \mu(3 \gamma-1)-5(4 \gamma-1)]+5(4 \gamma-1) \sqrt{-17 \gamma+25 \gamma^{2}+3}} \Delta\right]+t^{2} \gamma^{2} \\
& {\left[18 \gamma \mu\left(-10 \gamma+17 \mu+30 \gamma^{2}-95 \gamma \mu+130 \gamma^{2} \mu\right)-25(4 \gamma-1)\left(-17 \gamma+26 \gamma^{2}+3\right)+\right.} \\
& \left.\left.2 \gamma[25(4 \gamma-1)+18 \mu(13 \gamma \mu+5-15 \gamma-4 \mu)] \sqrt{-17 \gamma+25 \gamma^{2}+3}\right]\right\}>0
\end{aligned}
$$

Numerical simulations show that $[18 \mu(3 \gamma-1)-5(4 \gamma-1)]>0$,

$-1<\frac{5(4 \gamma-1)(3 \gamma-1)(1-\mu)}{\gamma[18 \mu(3 \gamma-1)-5(4 \gamma-1)]+5(4 \gamma-1) \sqrt{-17 \gamma+25 \gamma^{2}+3}}<1$ and

$\left[18 \gamma \mu\left(-10 \gamma+17 \mu+30 \gamma^{2}-95 \gamma \mu+130 \gamma^{2} \mu\right)-25(4 \gamma-1)\left(-17 \gamma+26 \gamma^{2}+3\right)+\right.$

$\left.2 \gamma[25(4 \gamma-1)+18 \mu(13 \gamma \mu+5-15 \gamma-4 \mu)] \sqrt{-17 \gamma+25 \gamma^{2}+3}\right]>0$ for $\mu>0.75 .{ }^{15}$ Hence, the whole expression is positive since due to Condition (3)

$\left[\frac{5}{6} t \gamma-\frac{5(4 \gamma-1)(3 \gamma-1)(1-\mu)}{\gamma[18 \mu(3 \gamma-1)-5(4 \gamma-1)]+5(4 \gamma-1) \sqrt{-17 \gamma+25 \gamma^{2}+3}} \Delta\right]>0$.

The above calculations show that $\delta_{W}^{G R}<\delta_{W}^{A C}$. Remember that we also found that $\underset{\delta_{A} \in \mathbb{R}}{\arg \min }\left(W_{G R}\right)<$ $0,\left.\frac{d W_{G R}}{d \delta_{A}}\right|_{\delta_{A}=0}>0, \underset{\delta_{A} \in \mathbb{R}}{\arg \min }\left(W_{A C}\right)<0,\left.\frac{d W_{A C}}{d \delta_{A}}\right|_{\delta_{A}=0}>0$, and $\left.\frac{d W_{A C}}{d \delta_{A}}\right|_{\delta_{A}=\delta_{W}^{A C}}>\left.\frac{d W_{G R}}{d \delta_{A}}\right|_{\delta_{A}=\delta_{W}^{A C}}$. Hence, we can neglect the intersection point between $W_{N E}$ and $W_{A C}$, since the policy maker would always prefer greenfield or acquisition entry to the right hand side of this point.

\section{(d) Entry Mode Pattern Preferred by the Social Planner}

It follows from the analysis above that the entry mode pattern the social planner prefers is increasing in the screening ability of the foreign bank: no entry - greenfield entry - acquisition entry. Again, one or both entry modes could drop out of the pattern depending on the parameter constellations, but the sequence of the pattern can never be different.

\section{Proof of Proposition 11:}

(1) Proof of $\delta_{A}^{C B L}<\widehat{\delta}_{A}^{G R}<\delta_{W}^{G R}$

Note that the policy maker cannot require that the foreign bank enters via a de novo investment if the foreign bank makes losses in case of greenfield entry. Hence, greenfield entry is only possible for $\pi_{A}^{G R} \geq 0$ which is equivalent to $\delta_{A} \geq \frac{1}{\mu(1-\gamma)\left(1+i_{A}\right)}\left(\frac{5}{2} \sqrt{\frac{t \gamma F_{G R}}{m}}-\frac{5}{6} t \gamma-\Delta\right) \equiv \widehat{\delta}_{A}^{G R}$. Note that $\widehat{\delta}_{A}^{G R}>\delta_{A}^{C B L}$ holds.

\footnotetext{
${ }^{15}$ In order to keep our analysis tractable, we henceforth assume $\mu>0.75$.
} 
(2) Proof of $\delta_{W}^{A C}>\delta_{A}^{A C}$

Note that $\delta_{W}^{A C}>\delta_{A}^{A C}$ is equivalent to

$\frac{6}{5}\left[25(15 \gamma+2 \mu-2 \gamma \mu-5)+9 \mu^{2}(-25 \gamma-8 \mu-10 \gamma \mu+20)\right]$

$\left[\frac{5}{6} t \gamma-\frac{25 \mu(1-\mu)(10 \gamma-1) \Delta}{\left(25(15 \gamma+2 \mu-2 \gamma \mu-5)+9 \mu^{2}(-25 \gamma-8 \mu-10 \gamma \mu+20)\right)}\right]<$

$15 \lambda\left[25(4 \gamma-1)-18 \mu^{2}(5 \gamma-2)\right] \sqrt{X_{A C}}+\frac{5}{3}\left(9 \mu^{2}-5\right) \sqrt{X_{A C}^{W}}$.

The right hand side of this expression is positive since $25(4 \gamma-1)-18 \mu^{2}(5 \gamma-2)>0$ as shown before. The left hand side is positive if $25(15 \gamma+2 \mu-2 \gamma \mu-5)+9 \mu^{2}(20-25 \gamma-8 \mu-10 \gamma \mu)>$ 0 and $\frac{5}{6} t \gamma-\frac{25 \mu(1-\mu)(10 \gamma-1) \Delta}{25(15 \gamma+2 \mu-2 \gamma \mu-5)+9 \mu^{2}(20-25 \gamma-8 \mu-10 \gamma \mu)}>0$. Numerical simulations show that the first expression is fulfilled and that $-1<\frac{30 \mu(1-\mu)(10 \gamma-1)}{25(15 \gamma+2 \mu-2 \gamma \mu-5)+9 \mu^{2}(-25 \gamma-8 \mu-10 \gamma \mu+20)}<1$ holds, which, in turn, guarantees that Condition (3) is fulfilled and, accordingly, $\frac{5}{6} t \gamma-$

$\frac{25 \mu(1-\mu)(10 \gamma-1) \Delta}{25(15 \gamma+2 \mu-2 \gamma \mu-5)+9 \mu^{2}(20-25 \gamma-8 \mu-10 \gamma \mu)}>0$ holds. Squaring both sides and rearranging yields

$$
\begin{aligned}
& \frac{t^{2} \gamma^{2}\left(400 \gamma+216 \mu^{2} \gamma-720 \mu \gamma-171 \mu^{2}+100\right)-12 \Delta(1-\mu)\left(27 \Delta-27 \mu \Delta-90 \gamma \Delta-70 t \gamma^{2}+10 t \gamma+90 \mu \gamma \Delta+135 \mu t \gamma^{2}-36 \mu t \gamma\right)}{25(4 \gamma-1)-18 \mu^{2}(5 \gamma-2)}< \\
& \frac{36 t \gamma}{m}\left(F_{G R}-F_{A C}\right)+\frac{90 \lambda \sqrt{X_{A C}^{W} \cdot X_{A C}}}{25(4 \gamma-1)-18 \mu^{2}(5 \gamma-2)} .
\end{aligned}
$$

The right hand side of this inequality is positive. The left hand side, however, is negative. To see this, note, first, that $\left(400 \gamma+216 \mu^{2} \gamma-720 \mu \gamma-171 \mu^{2}+100\right)<0$. Second, $27 \Delta-27 \mu \Delta-$ $90 \gamma \Delta-70 t \gamma^{2}+10 t \gamma+90 \mu \gamma \Delta+135 \mu t \gamma^{2}-36 \mu t \gamma>0$ is equivalent to $\frac{6}{5}(135 \mu \gamma+10-36 \mu-70 \gamma)$ $\left(\frac{5}{6} t \gamma-\frac{15(10 \gamma-3)(1-\mu)}{2(135 \mu \gamma+10-36 \mu-70 \gamma)} \Delta\right)>0$. Note that $-1<\frac{15(10 \gamma-3)(1-\mu)}{2(135 \mu \gamma+10-36 \mu-70 \gamma)}<1$ holds for not too small $(\gamma, \mu)$ combinations $^{16}$; then, $135 \mu \gamma+10-36 \mu-70 \gamma>0$ also holds. Accordingly, Condition (3) is fulfilled and it follows that $\frac{6}{5}(135 \mu \gamma+10-36 \mu-70 \gamma)\left(\frac{5}{6} t \gamma-\frac{15(10 \gamma-3)(1-\mu)}{2(135 \mu \gamma+10-36 \mu-70 \gamma)} \Delta\right)>0$. As a consequence, the left hand side of the above expression is negative. Hence, the above expression is true and, consequently, it holds that $\delta_{W}^{A C}>\delta_{A}^{A C}$.

(3) Proof of $\frac{d \delta_{W}^{G R}}{d\left(\frac{1}{t}\right)}<0$

$\frac{d \delta_{W}^{G R}}{d\left(\frac{1}{t}\right)}=-\frac{5 t^{2} \gamma}{12 \mu(1-\gamma)(3 \gamma-1)\left(1+i_{A}\right)}\left(\sqrt{25 \gamma^{2}-17 \gamma+3}-\gamma\right)<0$

\footnotetext{
${ }^{16}$ To keep our analysis tractable, we assume $\mu>\frac{5}{3} \frac{58 \gamma-13}{140 \gamma-39}$, which is slightly larger than 0.75 .
} 


\section{References}

Beermann, P., 2007. M\&A versus Greenfield - Optimal Entry Modes into Markets with Sequential Entry, in: Beermann, P., Topics in Multinational Banking and International Industrial Organization. Dissertation, Ludwig-Maximilians-University Munich.

Berger, A., 2007. Obstacles to a Global Banking System: 'Old Europe' versus 'New Europe'. Journal of Banking and Finance 31(7), 1955-1973.

Berger, A., Klapper, L., Martínez Pería, M.S., Zaidi, R., 2008. Bank Ownership Type and Banking Relationships. Journal of Financial Intermediation 17(1), 37-62.

Brainard, L., 1993. A Simple Theory of Multinational Corporations and Trade with a Trade-Off between Proximity and Concentration. NBER Working Paper 4269, Cambridge.

Buch, C., Lipponer, A., 2007. FDI versus Exports: Evidence from German Banks. Journal of Banking and Finance 31(3), 805-826.

Claessens, S., Van Horen, N., Gurcanlar, T., Mercado, J., 2008. Foreign Bank Presence in Developing Countries 1995-2006: Data and Trends. Working Paper, University of Amsterdam.

Claeys, S., Hainz, C., 2006. Acquisition versus Greenfield: The Impact of the Mode of Foreign Bank Entry on Information and Bank Lending Rates. ECB Working paper 653, Frankfurt.

Correa, R., 2008. Cross-Border Bank Acquisitions: Is there a Performance Effect? International Finance Discussion Papers 922, Washington.

De Haas, R., van Lelyveld, I., 2006. Foreign Banks and Credit Stability in Central and Eastern Europe. A Panel Data Analysis. Journal of Banking and Finance 30(7), 1927-1952.

Dell'Ariccia, G., 2001. Asymmetric Information and the Structure of the Banking Industry. European Economic Review 45(10), 1957-1980.

Dell'Ariccia, G., Friedman, E., Marquez, R., 1999. Adverse Selection as a Barrier to Entry in the Banking Industry. The RAND Journal of Economics 30(3), 515-534.

Dell'Ariccia, G., Marquez, R., 2004. Information and Bank Credit Allocation. Journal of Financial Economics 72(1), 185-214.

Eicher, T., Kang, J., 2005. Trade, Foreign Direct Investment or Acquisition: Optimal Entry Modes for Multinationals. Journal of Development Economics 77(1), 207-228.

Focarelli, D., Pozzolo, A., 2001. The Patterns of Cross-Border Bank Mergers and Shareholdings in OECD Countries. Journal of Banking and Finance 25(12), 2305-2337.

García Herrero, A., Martínez Pería, M.S., 2007. The Mix of International Banks' Foreign Claims: Determinants and Implications. Journal of Banking and Finance 31(6), 1613-1631.

Gilroy, B., Lukas, E., 2006. The Choice between Greenfield Investment and Cross-Border Acquisition: A Real Option Approach. The Quarterly Review of Economics and Finance 46, 447-465.

Görg, H., 2000. Analyzing Foreign Market Entry - The Choice between Greenfield Investment and Acquisitions. Journal of Economic Studies 27(3), 165-181.

Gormley, T., 2008. Costly Information, Foreign Entry, and Credit Access. AFA 2008 New Orleans Meetings Paper, Cambridge. 
Helpman, E., Melitz, M., Yeaple, S., 2004. Export versus FDI with Heterogeneous Firms. American Economic Review 94(1), 300-316.

Iranzo, S., 2003. FDI Mode of Entry and Acquisition of Firm Specific Assets. Working Paper, University of Sydney.

Köhler, M., 2008. Transparency of Regulation and Cross-Border Bank Mergers. ZEW Discussion Paper 08-009, Mannheim.

Maioli, S., Ferrett, B., Girma, S., Görg, H., 2006. The Market Disciplining Effects of FDI: Does the Mode of Entry Matter? University of Nottingham Research Paper 2006/16.

Majnoni, G., Shankar, R., Varhegyi, E., 2003. The Dynamics of Foreign Bank Ownership Evidence from Hungary. World Bank Policy Research Working Paper 3114, Washington.

Martínez Pería, M.S., Mody, A., 2004. How Foreign Participation and Market Concentration Impact Bank Spreads: Evidence from Latin America. Journal of Money, Credit and Banking 36(3), 511-537.

Müller, T., 2007. Analyzing Modes of Foreign Entry: Greenfield Investment versus Acquisition. Review of International Economics 15(1), 93-111.

Nocke, V., Yeaple, S., 2004. An Assignment Theory of Foreign Direct Investment. NBER Working Paper 11003, Cambridge.

Nocke, V., Yeaple, S., 2007. Cross-Border Mergers and Acquisitions vs. Greenfield Foreign Direct Investment: The Role of Firm Heterogeneity. Journal of International Economics 72(2), 336-365.

Peek, J., Rosengren, E., 2000. Implications of the Globalization of the Banking Sector: The Latin American Experience. New England Economic Review 2000/09, 45-62.

Petersen, M., Rajan, R., 1994. The Benefits of Lending Relationships: Evidence from Small Business Data. The Journal of Finance 49(1), 3-37.

Raff, H., Ryan, M., Staehler, F., 2006. Asset Ownership and Foreign Market Entry. CES-Ifo Working Paper 1676, Munich.

Sengupta, R., 2007. Foreign Entry and Bank Competition. Journal of Financial Economics 84(2), 502-528.

Stein, J., 2002. Information Production and Capital Allocation: Decentralized versus Hierarchical Firms. The Journal of Finance 57(5), 1891-1921.

Tekin-Koru, A., 2006. Is FDI Indeed Tariff-Jumping? Firm-Level Evidence. Working Paper, Oregon State University.

Van Tassel, E., Vishwasrao, S., 2007. Asymmetric Information and the Mode of Entry in Foreign Credit Markets. Journal of Banking and Finance 31, 3742-3760.

Vo Thi, N., Vencappa, D., 2007. Does the Entry Mode of Foreign Banks Matter for Bank Efficiency? Evidence from Czech Republic, Hungary, and Poland. Working Paper, University of Paris X at Nanterre. 